\title{
Moment-curvature damage model for bridges subjected to seismic loads
}

\author{
Sergio Oller *, Alex H. Barbat \\ Escuela de Ingenieros de Caminos Canales y Puertos, Universidad Politécnica de Cataluña, Jordi Girona 1-3, C1, 08034 Barcelona, Spain
}

Received 2 February 2005; received in revised form 29 August 2005; accepted 20 September 2005

\begin{abstract}
The evaluation of the damage caused by horizontal loads, such as seismic action, to existing bridges has received an important attention in recent years, because it is the first step towards reducing casualties and economic losses. In damage detection and evaluation, the application of simple and reliable models has been prioritized, because they are necessary in further multi-analyses required by Monte Carlo simulations. A simplified moment-curvature damage evaluation model, capable of evaluating the expected seismic behavior of RC highway bridges is proposed in this paper. The damage of a pier is related to the reduction of the cross-sectional moment of inertia of the bridge piers. Therefore, the evaluation of the damage is based on a non-linear analysis determining the changes of the mentioned moment of inertia. The model was validated using experimental results obtained at the JRC Ispra for the Warth Bridge of Austria and also FEM analyses performed by other authors for the same bridge.
\end{abstract}

(C) 2005 Elsevier B.V. All rights reserved.

Keywords: Damage estimation; Damage model; Moment-curvature; Seismic vulnerability; Fragility curves; Global damage

\section{Introduction}

Nowadays, the evaluation of the damage caused by earthquakes in existing bridges received great attention. Numerous researches devoted to the structural damage evaluation have been performed, most of them considering the seismic behavior of buildings. The structural damage in bridges can be treated considering the following concepts:

1. Local damage is evaluated at given points of the structure by means of local constitutive models describing the damage accumulation caused by micro-structural damage [16,24,26,39].

2. Global damage, evaluated starting from local damage, is a scalar depending on some variables (or damage parameters) that characterize the dynamic response of the whole system $[2,3,32]$.

In this paper, the seismic damage is evaluated at local level and then, global damage indices are obtained at cross-sectional, element and structural level by adequately as weighted averages of the local damage indices. The local damage index which describes the state of the material at each point of the structure, and which is the starting point of the proposed structural dynamic model, is based on an isotropic damage constitutive law. Details on this constitutive law are given in Appendix A of the paper. The global damage of each pier is obtained from reduction of the sectional moment of inertia

\footnotetext{
${ }^{*}$ Corresponding author. Fax: +34 934011048.

E-mail address: sergio.oller@upc.edu (S. Oller).
} 


\section{Nomenclature}

$\gamma_{c}, \gamma_{v} \quad$ mass density of piers and girders

$\Delta \mathbf{M}=\mathbf{M}^{0}-\mathbf{M}^{\text {int }}$ residual bending moment of a pier

$\mathbf{M}^{0}, \mathbf{M}^{\text {int }}$ maximum elastic external moment and pier internal strength capacity moment

$\boldsymbol{\varepsilon}, \boldsymbol{\sigma} \quad$ strain and stress tensor at a given point

$\hat{\boldsymbol{\sigma}}=\left\{\begin{array}{lll}N & M_{1} & M_{2}\end{array}\right\}$ generalized stresses at a given cross-section

$\hat{\boldsymbol{\varepsilon}}=\left\{\begin{array}{lll}\varepsilon^{N} & \chi_{1} & \chi_{2}\end{array}\right\}$ generalized strains at a given cross-section

$\tau^{*}, \tau \quad$ effective stress threshold and current effective stress

$\mathbf{U}=\left\{\begin{array}{lll}u & v_{1} & v_{2}\end{array}\right\}$ displacement vector of a pier

$\chi \quad$ curvature of the beam element

$\omega_{i} \quad$ cyclic frequency of mode $i$

$\Psi(\boldsymbol{\varepsilon} ; d), \Psi_{0}(\boldsymbol{\varepsilon})$ Helmholtz free energy and its elastic part

$a(t) \quad$ ground acceleration

A parameter of the isotropic damage model

A area of cross-section

$b, h \quad$ base and height of piers

d damage at a given point

$D_{i} \quad$ pier damage index

$D_{m} \quad$ global damage index

$E_{\mathrm{c}}^{0}, E_{\mathrm{c}}^{\mathrm{d}}$ initial and damaged Young's modulus of piers

$E_{\mathrm{h}}, E_{\mathrm{a}}$ Young's modulus for concrete and reinforced steel
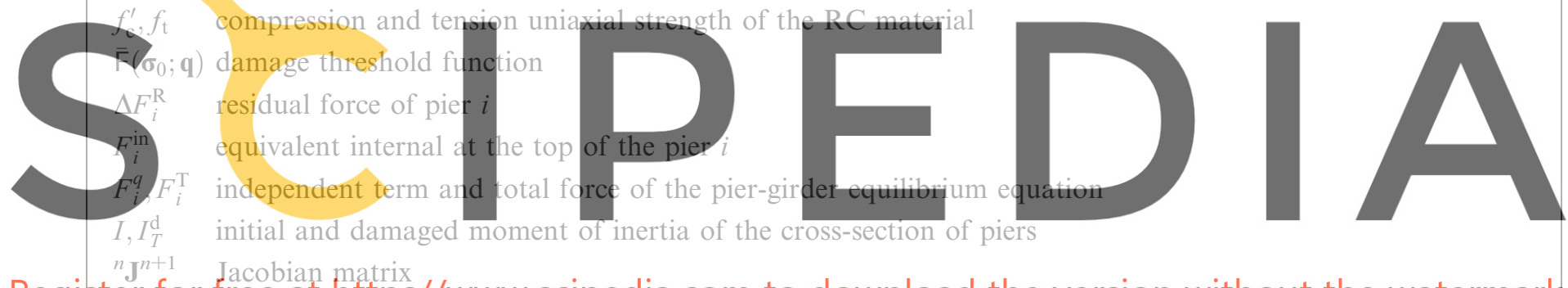

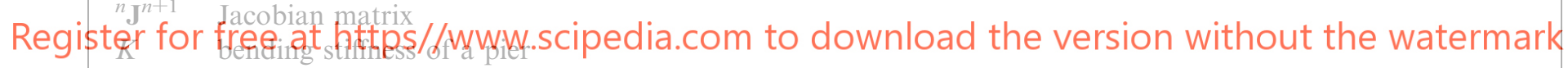

$k_{\mathrm{h}}, k_{\mathrm{a}}$ proportion of the concrete and reinforced steel area of an $\mathrm{RC}$ element

$K_{i}^{S} \quad$ equivalent rotational stifiness at the bottom of piers

$l_{\mathrm{c}}^{(j)} \quad$ distance between the neutral axis of the subsection $j$ and the axis of the section

$L \quad$ length of girders of length of the bridge

$L_{\mathrm{p}} \quad$ length of piers

$m_{i} \quad$ mass associated with mode shape $i$

$n_{\mathrm{p}} \quad$ number of piers of the bridge

$\left(q_{i}^{\text {in }}\right)^{\max }\left(q_{i}^{\text {in }}\right)^{\text {min }}$ maximum and minimum inertial load produced by the horizontal acceleration

$T_{0}, T_{\mathrm{f}}$ initial and final period of a given mode shape

TOL tolerance

$u_{\mathrm{p}} \quad$ relative displacement between the upper and lower part of the bearings

$x_{1}, x_{2}, x_{3}$ reference system

$X_{1}^{\mathrm{CG}}, X_{2}^{\mathrm{CG}}$ coordinates of neutral axes at the transversal section of piers

due to the material degradation. This analysis is based on a model able to work in biaxial bending and which is completely independent of the pier axis. The validation of the proposed pier model was performed by using the experimental tests on scale models of a pier of the Warth Bridge, Austria, carried out at the Joint Research Center of Ispra, Italy [35] and a FE model developed by Faria et al. [10] for the same pier. The simplifying hypotheses adopted in this work allowed incorporating the developed pier model in a dynamic model of the complete bridge, whose overall seismic behaviour is decisively influenced by the damage of the piers. 
The main objective of this paper is to develop a procedure to evaluate the seismic vulnerability of RC highway bridges with simple pier bents, a typology of bridges frequently used all over Europe during the period 1960-1980 and which is still widespread in many European countries. The structural model used to reach this objective is based on the hypothesis of the flexible pier-rigid deck behaviour for the structure subjected to seismic loads and works in bending, transversally to the bridge axis, according to the experimental evidence available for Warth Bridge $[10,13]$ and the numerical study shown in the paper. Thus, the study of the damage produced by horizontal loads has been focussed on the piers of the bridge [12], while the structural study of the deck should be performed after the analysis of the piers, in an uncoupled way. The damage of the piers is described by a pier damage index and a mean global damage index has been also proposed for the bridge.

The proposed structural model allows a simple, reliable and efficient structural analysis. Therefore, it is suitable for considering uncertainties in the structural and mechanical characteristics and in evaluating the seismic vulnerability of bridges based on fragility curves by means of Monte Carlo simulations. The model has been applied to develop fragility curves and damage probability matrices for the Warth Bridge and a summary of the results are shown in the paper.

\section{Description of the dynamic model}

Reinforced concrete highway bridges with simple pier bents have greater redundancy and higher strength in their longitudinal direction; therefore they will undergo greater damage when subjected to transversal seismic actions. The proposed model aims of studying the bridge response to horizontal loads acting transversal relative to the direction of the bridge axis. Experimental studies confirm that the structural system can be modelled simply by piers loaded transverse to the axis of the bridge interconnected at the deck level by means of box girders [12,28]. Due to the high stiffness of the bridge in the longitudinal direction, the structural analysis in this direction is out of the purposes of this work, focusing on the structural study of the pier in the transverse direction.

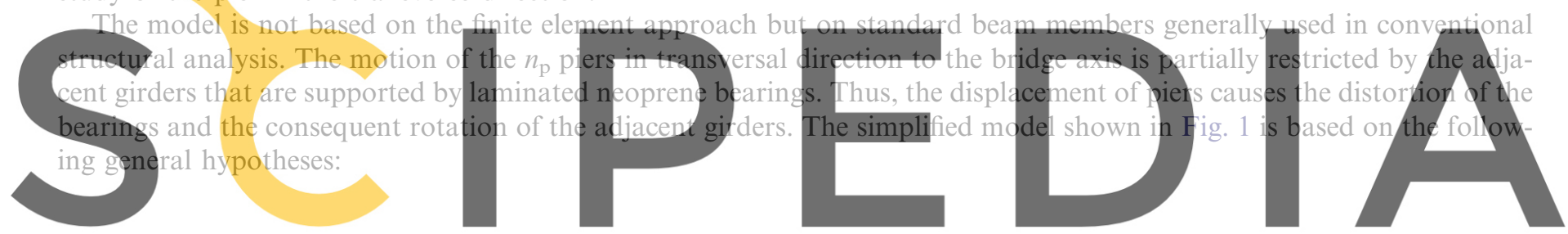

Register for free at https//www.scipedia.com to download the version without the watermark

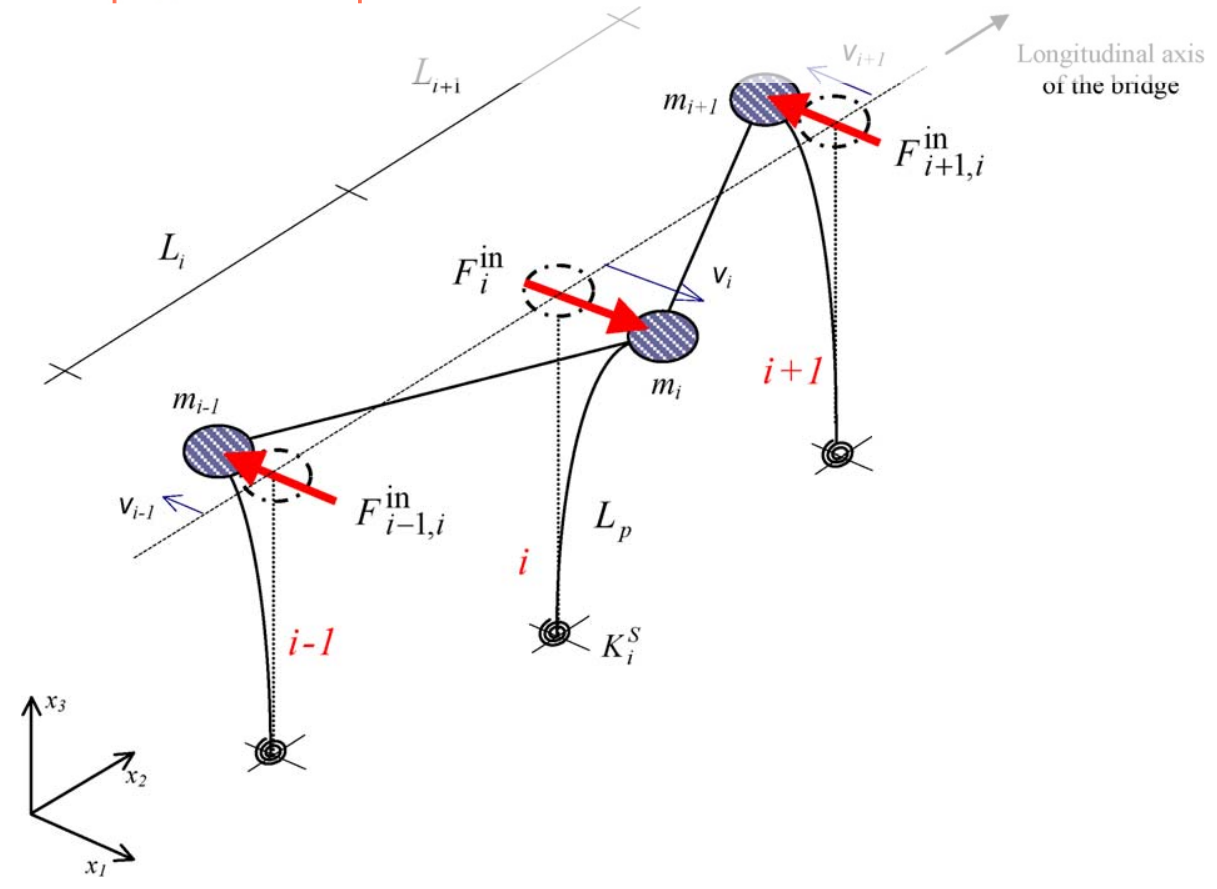

Fig. 1. Model for the seismic analysis of the bridge. 
1. The piers are continuous elements with distributed mass and infinite axial stiffness.

2. The girders are perfectly stiff elements concentrating the mass at the top of the piers.

3. The bearings of the girders are equivalent linear short elements that work in shear, having circular cross-section.

4. The soil-structure interaction effect on piers and abutments is considered by means of linear springs that represent the rotational stiffness of the soil.

5. The abutments are perfectly stiff.

Accordingly, the model has as many degrees of freedom as transversal displacements at the top of the piers, that is, $n_{\mathrm{p}}$ degrees of freedom. In following sections, the traverse stiffness of an isolated pier under non-linear damage effects produced by a horizontal load applied at the deck level will be studied.

\subsection{Transversal behaviour of a single pier}

According to the general hypotheses and to Fig. 2, the maximum displacement at the top of a pier is

$$
\mathrm{v}_{i}=\mathrm{v}_{\theta}^{i}+\mathrm{v}_{\mathrm{p}}^{i}
$$

where

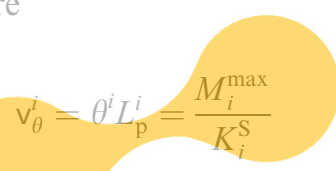

is the elastic displacement produced by a rotation at the base of the pier, and
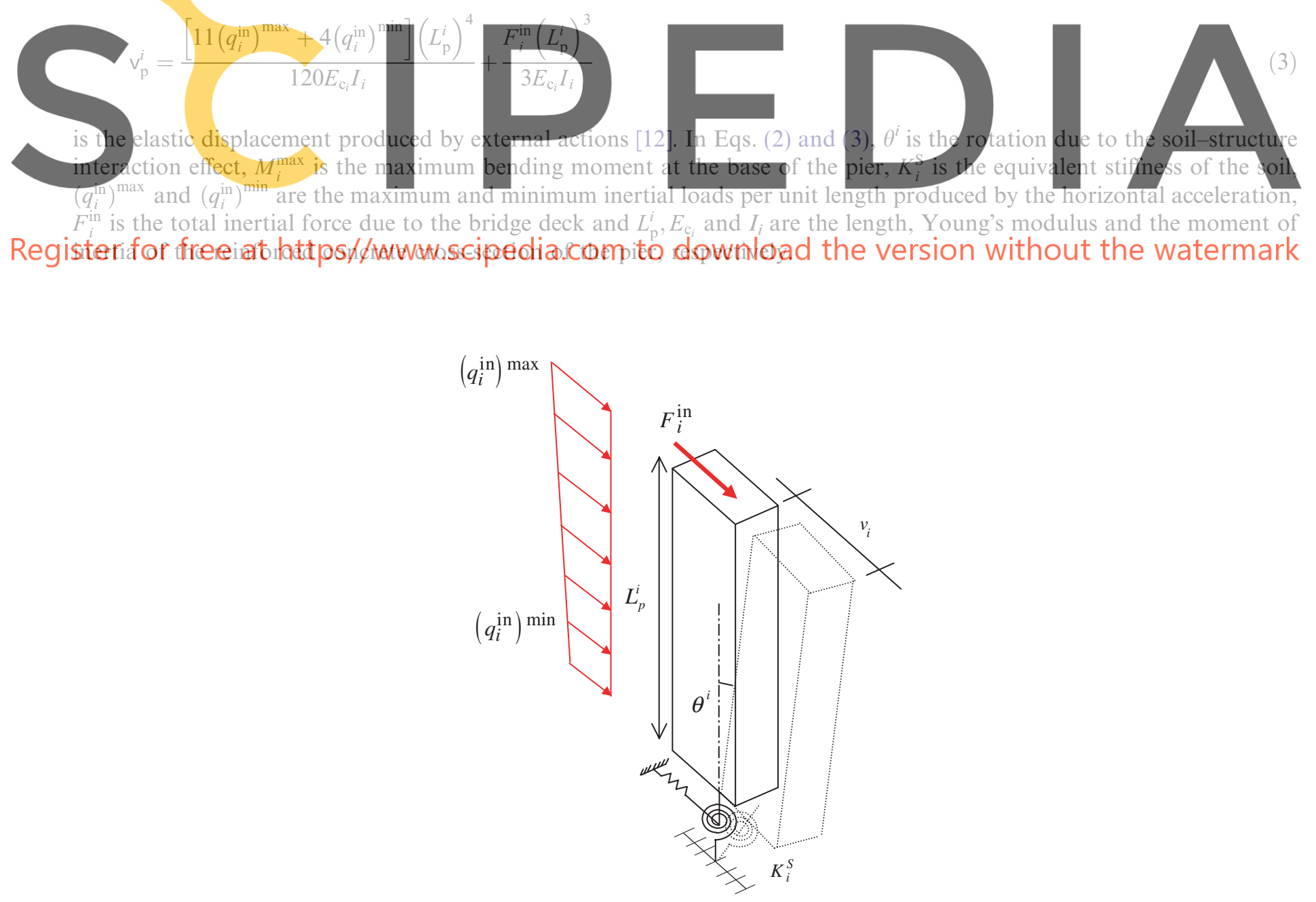

Fig. 2. Transversal displacements of pier $I$ considering the soil effect. 
For the maximum moment of the pier (for $x_{3}=0$ ), the bending moment equation is [12]

$$
M_{i}\left(x_{3}=0\right)=M_{i}^{\max }=\frac{\left[2\left(q_{i}^{\text {in }}\right)^{\max }+\left(q_{i}^{\text {in }}\right)^{\min }\right]\left(L_{\mathrm{p}}^{i}\right)^{2}}{6}+\left(F_{i}^{\text {in }} L_{\mathrm{p}}^{i}\right) .
$$

Substituting Eqs. (2)-(4) into Eq. (1), the equivalent internal force at the top of the pier is obtained as a function of the maximum displacement $v_{i}$ of the pier

$$
F_{i}^{\mathrm{in}}=\frac{1}{\left[\frac{L_{\mathrm{p}}^{i}}{K_{i}^{\mathrm{S}}}+\frac{\left(L_{\mathrm{p}}^{i}\right)^{3}}{3 E_{\mathrm{c}_{i}} I_{i}}\right]}\left[v_{i}-\frac{\left[2\left(q_{i}^{\mathrm{in}}\right)^{\max }+\left(q_{i}^{\mathrm{in}}\right)^{\min }\right]\left(L_{\mathrm{p}}^{i}\right)^{2}}{6 K_{i}^{\mathrm{S}}}-\frac{\left[11\left(q_{i}^{\mathrm{in}}\right)^{\max }+4\left(q_{i}^{\mathrm{in}}\right)^{\min }\right]\left(L_{\mathrm{p}}^{i}\right)^{4}}{120 E_{\mathrm{c}_{i}} I_{i}}\right] .
$$

\section{Non-linear analysis of the pier}

When the non-linear behavior of the structural materials is taken into account, the undamped lumped mass equation of motion for each pier is written as

$$
m_{i} a_{i}+F_{i}^{\mathrm{in}}-\Delta F_{i}^{\mathrm{R}}=0,
$$

where $m_{i}$ is the part of the mass of the girder and pier associated to $i$ th degree of freedom and $\Delta F_{i}^{\mathrm{R}}$ is the residual or out-ofbalance force. This unbalanced force is due to the fact that the cross-section moment of inertia and Young modulus are not constant during the non-linear process and consequently the solution of Eq. (6) should be obtained throughout an iterative
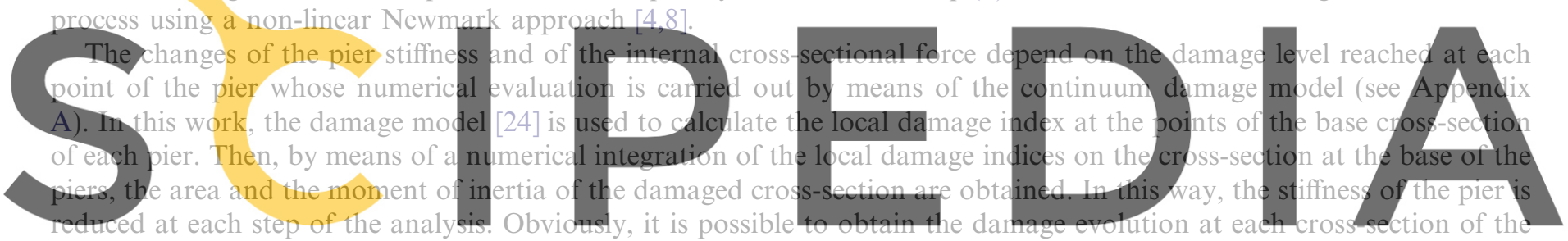

pier, but the moment-curvature model requires the evaluation of damage only at the most loaded section, which is the base

Registegefionfree at https//www.scipedia.com to download the version without the watermark

To obtain the response and the maximum damage of all the bridge piers using the proposed model, Newmark's non-

linear algorithm, summarized in Box 1, is used to solve the equilibrium equation at each time of the process. In this analysis, the force equilibrium condition is achieved by eliminating $\Delta \mathbf{F}_{i}^{R}$ using a Newton-Raphson process. Indirectly, this process also eliminates the residual bending moment $\Delta \mathbf{M}=\mathbf{M}^{0}-\mathbf{M}^{\text {int }}$ included in the residual force array, which is the difference between the maximum elastic external moment, $\mathbf{M}^{0}$, and the pier internal strength capacity moment, $\mathbf{M}^{\text {int }}$. For each step of the non-linear analysis the properties of the system are updated, considering the local degradation of the material caused by the seismic action.

\subsection{Solution of the dynamic equation of equilibrium}

The steps to define the damage in any pier of the bridge are described in Boxes 1 and 2. The maximum global damage index of the structure is obtained starting from the cross-sectional damage calculated at the base of the piers for transversal seismic actions. Box 1 shows the numerical procedure to solve the dynamic equilibrium equation (6) using Newmark's nonlinear integration method. As shown previously, the type of bridge under study is modeled by means of piers that behave like cantilever beams, for which the numerical integration of the damage on the cross-section can be simplified, considering in the analysis only the cross-section at the pier base, that is, for $x_{3}=0$. Nevertheless, the procedure could be generalized including when necessary other cross-sections at levels $x_{3}$ in the damage integration procedure.

\section{Study of the damaged cross-section for skew bending}

\subsection{Theoretical aspects}

Different distributed damage of reinforced concrete structures have been proposed by several authors [23,33,34]. These formulations are adequate to represent the behavior of beams subjected to compression with biaxial bending. An 
Box 1. Solution of the non-linear equilibrium equation applied for the bridge using Newmark's method

1. Displacement and velocity prediction at " $t+\Delta t$ ", starting from null initial conditions

$$
\left.\begin{array}{l}
\ddot{\widetilde{\mathbf{U}}}^{t+\Delta t}=0 ; \quad \dot{\tilde{\mathbf{U}}}^{t+\Delta t}=\dot{\mathbf{U}}^{t}+(1-\gamma) \ddot{\mathbf{U}}^{t} \Delta t \\
\widetilde{\mathbf{U}}^{t+\Delta t}=\mathbf{U}^{t}+\dot{\mathbf{U}}^{t} \Delta t+\left(\frac{1}{2}-\beta\right) \ddot{\mathbf{U}}^{t} \Delta t^{2} ; \quad{ }^{i} \Delta \mathbf{f}^{t+\Delta t}=\mathbf{F}_{i}^{q}
\end{array}\right\} \gamma=0.5, \quad \beta=0.25 .
$$

2. Computation of displacement increment $\Delta \mathbf{U}^{t+\Delta t}$ at instant $t+\Delta t$, starting from the linearized equilibrium equation

$$
{ }^{i} \Delta \mathbf{f}^{t+\Delta t}={ }^{i} \mathbf{J}^{t+\Delta t i+1} \Delta \ddot{\mathbf{U}}^{t+\Delta t} ; \quad{ }^{i} \mathbf{J}^{t+\Delta t}={ }^{i}\left[\mathbf{M} \cdot\left(\frac{1}{\beta \Delta t^{2}}\right)+\mathbf{K}\right]^{t+\Delta t} .
$$

3. Displacement and velocity correction

$$
{ }^{i+1} \ddot{\mathbf{U}}^{t+\Delta t}=\left(\frac{1}{\beta \Delta t^{2}}\right){ }^{i+1} \Delta \ddot{\mathbf{U}}^{t+\Delta t} ; \quad{ }^{i+1} \dot{\mathbf{U}}^{t+\Delta t}=\dot{\tilde{\mathbf{U}}}^{t+\Delta t}+\left(\frac{\gamma}{\beta \Delta t}\right){ }^{i+1} \Delta \mathbf{U}^{t+\Delta t} ; \quad{ }^{i+1} \mathbf{U}^{t+\Delta t}=\widetilde{\mathbf{U}}^{t+\Delta t}+{ }^{i+1} \Delta \mathbf{U}^{t+\Delta t} .
$$

4. Loop over $k$ bridge piers. The damage constitutive equation is computed at each pier $k$ and at each cross-section (see next section and Box 2 for more details).

4a. Computation of the generalized forces (predictor) and the elastic curvatures and axial strain at each cross-section $x_{3}$, using the displacement ${ }^{i+1} \mathbf{U}^{t+\Delta t}$ at the top of pier $k$

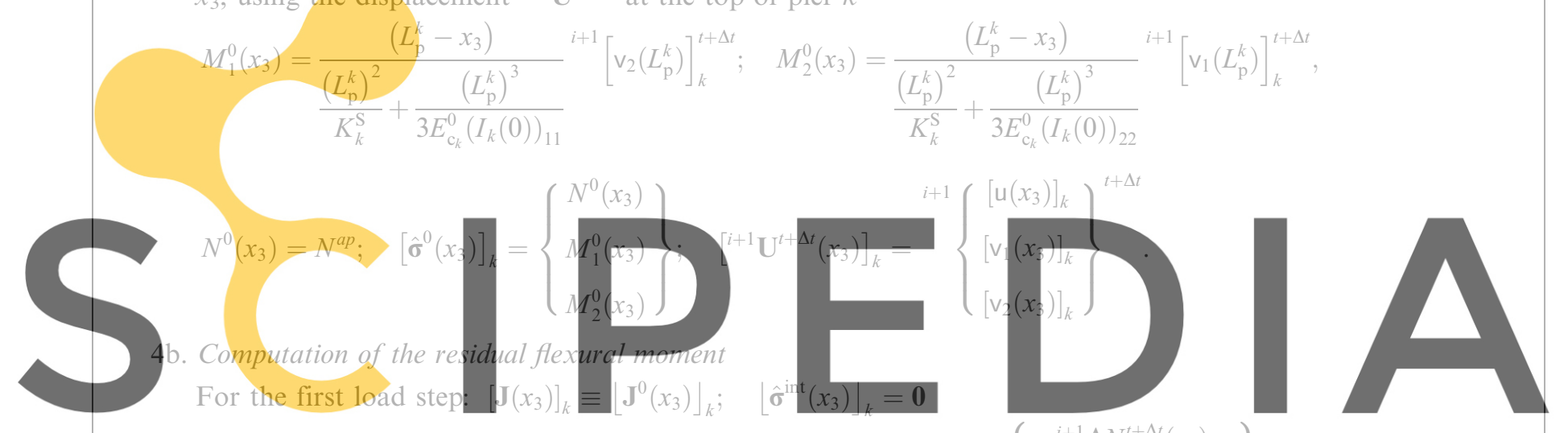

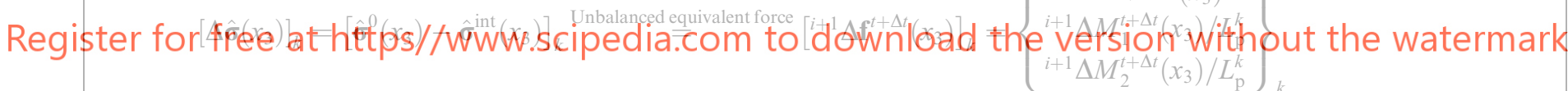

4c. Equilibrium equation verification on the clamped cross-section

$$
\|\Delta \hat{\boldsymbol{\sigma}}(0)\| \stackrel{?}{=} \begin{cases}0 & \Rightarrow \text { go to } E X I T, \\ \neq 0 & \Rightarrow \text { Continue. }\end{cases}
$$

4d. Computation of the incremental generalized strains and their current value

$$
\begin{aligned}
& {\left[{ }^{n+1} \Delta \hat{\boldsymbol{\varepsilon}}^{t+\Delta t}(0)\right]_{k}=-\left[{ }^{n} J^{n+1}(0)\right]_{k}^{-1}\left[{ }^{n} \Delta \hat{\boldsymbol{\sigma}}^{t+\Delta t}(0)\right]_{k},} \\
& {\left[{ }^{n+1} \hat{\boldsymbol{\varepsilon}}^{t+\Delta t}(0)\right]_{k}=\left[{ }^{n} \hat{\boldsymbol{\varepsilon}}^{t+\Delta t}(0)\right]_{k}+\left[{ }^{n+1} \Delta \hat{\boldsymbol{\varepsilon}}^{t+\Delta t}(0)\right]_{k} .}
\end{aligned}
$$

4e. Damaged moment of inertia at the base cross-section of pier $k$ (see Box 2).

5. Back to point $4 b$ followed by the minimization of generalized unbalanced force equation.

6. Calculate the displacement at each point $x_{3}$ of the pier and EXIT

$$
\begin{aligned}
& {\left[{ }^{i+1} U^{t+\Delta t}\left(x_{3}\right)\right]_{k}=\left\{\begin{array}{l}
{\left[\mathrm{u}\left(x_{3}\right)\right]_{k}} \\
{\left[\mathrm{v}_{1}\left(x_{3}\right)\right]_{k}} \\
{\left[\mathrm{v}_{2}\left(x_{3}\right)\right]_{k}}
\end{array}\right\}^{t+\Delta t}=\left\{\begin{array}{l}
{\left[\mathrm{u}\left(x_{3}-\Delta x_{3}\right)\right]_{k}} \\
{\left[\mathrm{v}_{1}\left(x_{3}-\Delta x_{3}\right)\right]_{k}} \\
{\left[\mathrm{v}_{2}\left(x_{3}-\Delta x_{3}\right)\right]_{k}}
\end{array}\right\}^{t+\Delta t}-\left\{\begin{array}{l}
{\left[\varepsilon^{N}\left(x_{3}-\Delta x_{3}\right)\right]_{k} \cdot \Delta x_{3}} \\
{\left[\varphi_{2}\left(x_{3}-\Delta x_{3}\right)\right]_{k} \cdot \Delta x_{3}} \\
{\left[\varphi_{1}\left(x_{3}-\Delta x_{3}\right)\right]_{k} \cdot \Delta x_{3}}
\end{array}\right\}^{t+\Delta t}+\left\{\begin{array}{c}
i+1 \\
\frac{\left[x_{2}\left(x_{3}-\Delta x_{3}\right)\right]_{k}}{2} \cdot \Delta x_{3}^{2} \\
{\left[\frac{\left.\chi_{1}\left(x_{3}-\Delta x_{3}\right)\right]_{k}}{2} \cdot \Delta x_{3}^{2}\right.}
\end{array}\right\}^{t+\Delta t},} \\
& \left\{\begin{array}{l}
{\left[\varphi_{1}\left(x_{3}\right)\right]_{k}} \\
{\left[\varphi_{2}\left(x_{3}\right)\right]_{k}}
\end{array}\right\}^{t+\Delta t}=\left\{\begin{array}{l}
{\left[\varphi_{1}\left(x_{3}-\Delta x_{3}\right)\right]_{k}} \\
{\left[\varphi_{2}\left(x_{3}-\Delta x_{3}\right)\right]_{k}}
\end{array}\right\}^{t+\Delta t}+\left\{\begin{array}{l}
{\left[\chi_{1}\left(x_{3}-\Delta x_{3}\right)\right]_{k} \cdot \Delta x_{3}} \\
{\left[\chi_{2}\left(x_{3}-\Delta x_{3}\right)\right]_{k} \cdot \Delta x_{3}}
\end{array}\right\}^{t+\Delta t} .
\end{aligned}
$$

7. Back to point 2 after the damage evaluation for all the piers and equilibrium equation for the complete bridge.

Verification of the condition $\left\|{ }^{i} \Delta \mathbf{f}^{t+\Delta t}\right\| \rightarrow 0$.

8. New time increment and dynamic load application over all the bridge. Back to point 1 . 
Box 2. Algorithm for the cross-sectional damage integration

1. Loop over the time $t+\Delta t$.

2. Loop over the cross-section position $x_{3}$.

3. Compute the elastic generalized stresses-predictor-for each cross-section.

4. Compute the residual generalized internal stresses

For the first load step: $J\left(x_{3}\right) \equiv J^{0}\left(x_{3}\right) ; \quad \hat{\boldsymbol{\sigma}}^{\text {int }}\left(x_{3}\right)=0 ; \quad \Delta \hat{\boldsymbol{\sigma}}\left(x_{3}\right)=\left[\hat{\boldsymbol{\sigma}}^{0}\left(x_{3}\right)-\hat{\boldsymbol{\sigma}}^{\text {int }}\left(x_{3}\right)\right]$

5. Equilibrium equation verification on $x_{3}$ cross-section:

$$
\left\|\Delta \hat{\boldsymbol{\sigma}}\left(x_{3}\right)\right\| \stackrel{?}{=} \begin{cases}0 & \Rightarrow \text { go to } E X I T \\ \neq 0 & \Rightarrow \text { Continue }\end{cases}
$$

6. Starting loop over Newton-Raphson $n^{\text {iteration }}$ process. Incremental generalized strain computation and obtaining of its current value:

$$
\begin{gathered}
{ }^{n+1} \Delta \hat{\boldsymbol{\varepsilon}}^{t+\Delta t}\left(x_{3}\right)=-\left[{ }^{n} J^{n+1}\left(x_{3}\right)\right]^{-1}{ }^{n} \Delta \hat{\boldsymbol{\sigma}}^{t+\Delta t}\left(x_{3}\right) \\
{ }^{n+1} \hat{\mathcal{E}}^{t+\Delta t}\left(x_{3}\right)={ }^{n} \widehat{\mathcal{E}}^{t+\Delta t}\left(x_{3}\right)+{ }^{n+1} \Delta \hat{\varepsilon}^{t+\Delta t}\left(x_{3}\right)
\end{gathered}
$$

7. Moment of inertia of the damaged cross-section of pier $k$ calculated at each $x_{3}$ using the continuum damage model showed in Box A.1 of Appendix A:

${ }^{n+1}\left[\sigma^{0}\right]^{t+\Delta t}\left(x_{1}, x_{2}, x_{3}\right)=E^{0} \cdot{ }^{n+1} x^{T} \cdot{ }^{n} \hat{\boldsymbol{\varepsilon}}^{t+\Delta t}\left(x_{3}\right)$

$f\left(\sigma^{0}\right)-{ }^{n}[c(f)]^{t+\Delta t}\{\leqslant 0$ Maintain the inertia value and go to $(* *)$

$f\left(\sigma^{0}\right)-[c(f)]\{$ The process of damage continues $(*)$
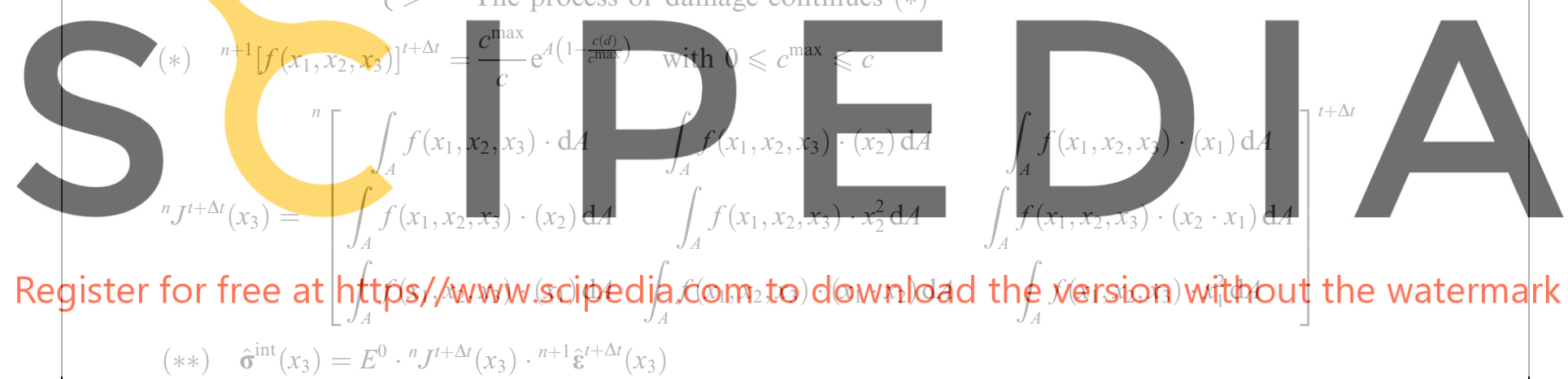

${ }^{n+1} \sigma^{t+\Delta t}\left(x_{1}, x_{2}, x_{3}\right)=E^{0}\left(x_{1}, x_{2}, x_{3}\right) \cdot{ }^{n+1} x^{T} \cdot{ }^{n} \hat{\boldsymbol{\varepsilon}}^{t+\Delta t}\left(x_{3}\right)$

8. Back to point 4

9. EXIT

alternative local constitutive stress-strain formulation is incorporated into the dynamic structural model which is proposed in this paper. A general isotropic damage and plasticity model, completely framed within the 3D continuous mechanic theory, was developed in previous works [19]. This model allows any cyclic numerical simulation, including the more general fatigue behavior, the effect of shear stress, the local and the global stability [29,36]. Moreover, this constitutive model allows dealing with several kinds of non-linearities in composite materials, including the debounding effect between steel and concrete [5]. Obviously, this general model is not used at its complete capacity in this paper, in which cyclic but not fatigue effect was considered, while the sliding effect between steel and concrete, the shear stresses and the instability effects were neglected. These simplifications are due to the main objective of this research, which was to perform seismic vulnerability evaluations of bridges based on fragility curves. For such an evaluation, Monte Carlo simulations are required, based on simplified dynamic and constitutive models adequate for massive multi-analysis of structures. This constitutive damage model is then included in the classical moment-curvature structural analysis.

In order to compute the moment of inertia and the bending moment of the damaged base cross-section of a pier required by the solution of the non-linear equation (6) - see Box 1-the isotropic damage model [24] has been applied (see Appendix A). In this section, the way of computing the local damage and its contribution to the cross-sectional damage of a pier is 


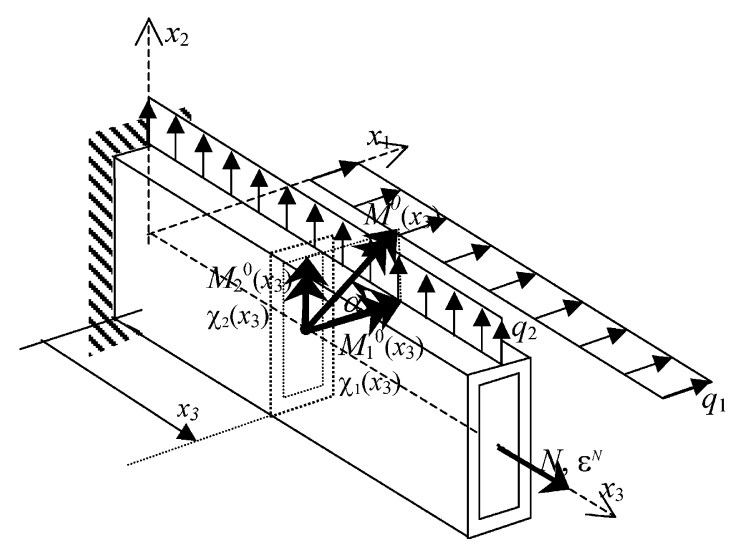

Fig. 3. Bridge pier represented as a cantilever Bernoulli beam.

described for Bernoulli beams subjected to skew bending. For this purpose, the damaged cantilever beam under skew bending of Fig. 3 is considered.

The external loads produce the following generalized forces in a cross-section located at a distance $x_{3}$

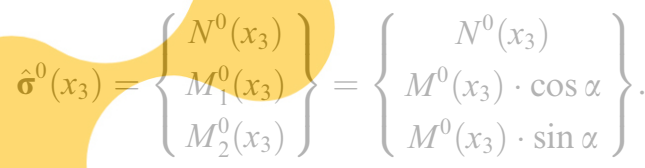

The following strain and curvature of the Bernoulli beam, due to the elastic bending moment of Eq. (7), will be taken as the predictor variables of the algorithm
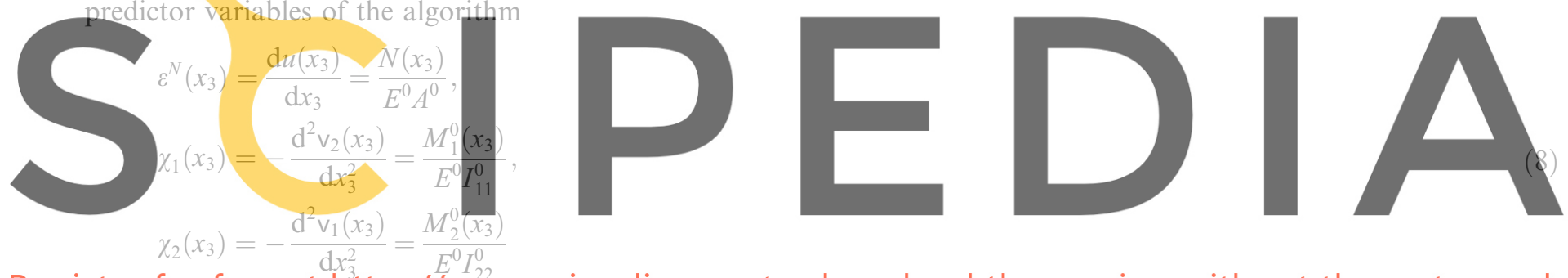

Register for free at https//wWw.scipedia.com to download the version without the watermark being $E^{0}$ the initial undamaged elasticity module, $A$ the initial area of the undamaged cross-section and $I_{i i}^{0}$ the initial moment of inertia of the undamaged cross-section regarding the principal reference system for $x_{i} \forall i=1,2$.

Considering the Bernoulli beam basic hypotheses, the following expressions for the strain and stress fields are obtained:

$$
\left\{\begin{aligned}
\varepsilon\left(x_{1}, x_{2}, x_{3}\right) & =\varepsilon^{N}\left(x_{3}\right)+\chi_{1}\left(x_{3}\right) \cdot x_{2}+\chi_{2}\left(x_{3}\right) \cdot x_{1}=\frac{N^{0}\left(x_{3}\right)}{E^{0} A^{0}}+\frac{M_{1}^{0}\left(x_{3}\right)}{E^{0} I_{11}^{0}} x_{2}+\frac{M_{2}^{0}\left(x_{3}\right)}{E^{0} I_{22}^{0}} x_{1} \\
& =\left\{\begin{array}{lll}
1 & x_{2} & x_{1}
\end{array}\right\} \cdot\left[\begin{array}{ccc}
E^{0} A^{0} & 0 & 0 \\
0 & E^{0} I_{11}^{0} & 0 \\
0 & 0 & E^{0} I_{22}^{0}
\end{array}\right]^{-1} \cdot\left\{\begin{array}{l}
N^{0}\left(x_{3}\right) \\
M_{1}^{0}\left(x_{3}\right) \\
M_{2}^{0}\left(x_{3}\right)
\end{array}\right\} . \\
\sigma\left(x_{1}, x_{2}, x_{3}\right) & =E^{0} \cdot \varepsilon\left(x_{1}, x_{2}, x_{3}\right)=\frac{N^{0}\left(x_{3}\right)}{A^{0}}+\frac{M_{1}^{0}\left(x_{3}\right)}{I_{11}^{0}} x_{2}+\frac{M_{2}^{0}\left(x_{3}\right)}{I_{22}^{0}} x_{1} \\
& =\left\{\begin{array}{lll}
1 & x_{2} & x_{1}
\end{array}\right\} \cdot\left[\begin{array}{ccc}
A^{0} & 0 & 0 \\
0 & I_{11}^{0} & 0 \\
0 & 0 & I_{22}^{0}
\end{array}\right]^{-1} \cdot\left\{\begin{array}{l}
N^{0}\left(x_{3}\right) \\
M_{1}^{0}\left(x_{3}\right) \\
M_{2}^{0}\left(x_{3}\right)
\end{array}\right\} \\
& =x^{T} \cdot\left[J^{0}\right]^{-1} \cdot \hat{\boldsymbol{\sigma}}^{0}\left(x_{3}\right) .
\end{aligned}\right.
$$

All the previous descriptions have been made for a linear elastic skew axial-bending problem. Thus, the material has limitless capacity to resist the applied loads as expressed in Eq. (9). This threshold is not possible to be reached for a real material, because its strength is limited to $c^{\max }$, as it can be seen in Eq. (A.8) of Appendix A. Therefore, the initial generalized internal forces $\hat{\boldsymbol{\sigma}}^{0}\left(x_{3}\right)$ produced by the external loads $\mathbf{F}^{0}\left(x_{3}\right)$ are initially unbalanced with the generalized internal stresses 
$\hat{\boldsymbol{\sigma}}\left(x_{3}\right)$, producing unbalanced residual generalized internal forces $\Delta \hat{\boldsymbol{\sigma}}\left(x_{3}\right)$. These residual stresses should be zero due to the equilibrium condition and this state is reached by increasing the curvature $\Delta \chi\left(x_{3}\right)$ and axial strain $\Delta \varepsilon^{N}\left(x_{3}\right)$ of the beam. Observe that the plane cross-section hypothesis is used only during the predictor estimation step inside the linearization loop (Box 1, point 4e). After the integration of the constitutive model (Box 2), the planarity hypothesis of the cross-section is not fulfilled due to the damage in some of its points. This iterative procedure starts with the linearization of the following unbalanced equilibrium equation at each cross-section of the beam:

$$
\begin{aligned}
& \Delta \hat{\boldsymbol{\sigma}}\left(x_{3}\right)=\left[\hat{\boldsymbol{\sigma}}^{0}\left(x_{3}\right)-\hat{\boldsymbol{\sigma}}^{\text {int }}\left(x_{3}\right)\right] \rightarrow \mathbf{0}, \\
& \left.\left\{\begin{array}{c}
\Delta N\left(x_{3}\right) \\
\Delta M_{1}\left(x_{3}\right) \\
\Delta M_{2}\left(x_{3}\right)
\end{array}\right\}=\left[\begin{array}{l}
N^{0}\left(x_{3}\right) \\
M_{1}^{0}\left(x_{3}\right) \\
M_{2}^{0}\left(x_{3}\right)
\end{array}\right\}-\left\{\begin{array}{c}
\int_{A} \sigma\left(x_{1}, x_{2}, x_{3}\right) \cdot \mathrm{d} A \\
\int_{A} \sigma\left(x_{1}, x_{2}, x_{3}\right) \cdot x_{2} \mathrm{~d} A \\
\int_{A} \sigma\left(x_{1}, x_{2}, x_{3}\right) \cdot x_{1} \mathrm{~d} A
\end{array}\right\}\right] \mathbf{0},
\end{aligned}
$$

where the stress at each point of the cross-section is obtained by using the constitutive damage model briefly described by the following equations:

$$
\begin{aligned}
& \sigma\left(x_{1}, x_{2}, x_{3}\right)=E\left(x_{1}, x_{2}, x_{3}\right) \cdot \varepsilon\left(x_{1}, x_{2}, x_{3}\right)=E\left(x_{1}, x_{2}, x_{3}\right) \cdot\left\lfloor\varepsilon^{N}\left(x_{3}\right)+x_{1}\left(x_{3}\right) \cdot x_{2}+x_{2}\left(x_{3}\right) \cdot x_{1}\right\rfloor \\
& \text { with: } E\left(x_{1}, x_{2}, x_{3}\right)=f\left(x_{1}, x_{2}, x_{3}\right) \cdot E^{0} .
\end{aligned}
$$

According to Appendix A, the evolution of the local damage internal variable at each point of each cross-section of the Bernoulli beam, obtained from the local damage constitutive model, is $f\left(x_{1}, x_{2}, x_{3}\right)=\left(1-d\left(x_{1}, x_{2}, x_{3}\right)\right)=\frac{c^{\max }}{c} \mathrm{e}^{A\left(1-\frac{c(d)}{c^{\max }}\right)}$, with $0 \leqslant c^{\max } \leqslant c$. The values $c^{\max }$ and $c$ are the maximum and current tension strength at each point of the solid, $A$ is a parameter depending of the fracture energy and $E\left(x_{1}, x_{2}, x_{3}\right)=f\left(x_{1}, x_{2}, x_{3}\right) \cdot E^{0}$ is the damaged elastic modulus. Substituting this expression in Eq. (10), the residual forces become
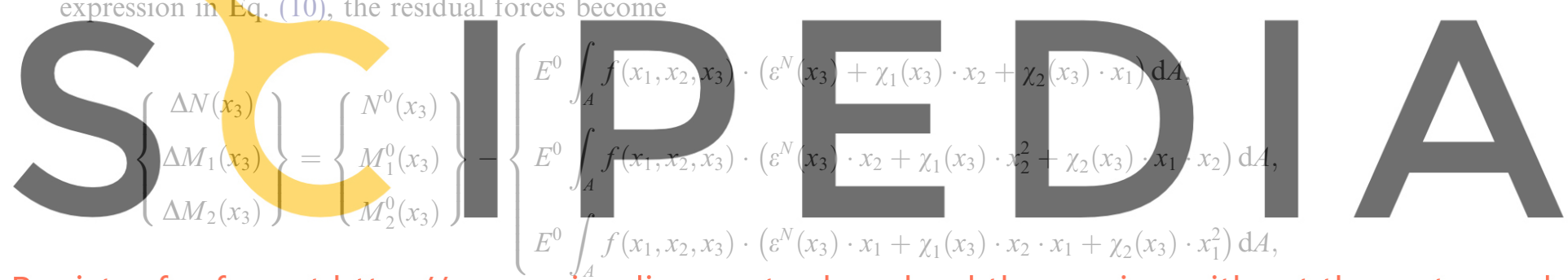

Register for free at https//www.scipedia.com to download the version without the watermark

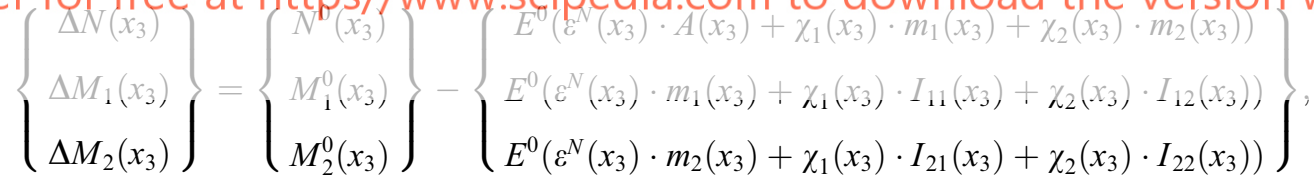

$$
\left\{\begin{array}{c}
\Delta N\left(x_{3}\right) \\
\Delta M_{1}\left(x_{3}\right) \\
\Delta M_{2}\left(x_{3}\right)
\end{array}\right\}=\left\{\begin{array}{l}
N^{0}\left(x_{3}\right) \\
M_{1}^{0}\left(x_{3}\right) \\
M_{2}^{0}\left(x_{3}\right)
\end{array}\right\}-E^{0}\left[\begin{array}{lll}
A\left(x_{3}\right) & m_{1}\left(x_{3}\right) & m_{2}\left(x_{3}\right) \\
m_{1}\left(x_{3}\right) & I_{11}\left(x_{3}\right) & I_{12}\left(x_{3}\right) \\
m_{2}\left(x_{3}\right) & I_{21}\left(x_{3}\right) & I_{22}\left(x_{3}\right)
\end{array}\right]\left\{\begin{array}{l}
\varepsilon^{N}\left(x_{3}\right) \\
\chi_{1}\left(x_{3}\right) \\
\chi_{2}\left(x_{3}\right)
\end{array}\right\},
$$

$\Delta \hat{\boldsymbol{\sigma}}\left(x_{3}\right)=\hat{\boldsymbol{\sigma}}^{0}\left(x_{3}\right)-E^{0}[\mathbf{J}] \cdot \hat{\boldsymbol{\varepsilon}}\left(x_{3}\right)$.

In this equation, $A\left(x_{3}\right)=\int_{A} f\left(x_{1}, x_{2}, x_{3}\right) \cdot \mathrm{d} A$ is the damaged cross-section, $m_{i}\left(x_{3}\right)=\int_{A} f\left(x_{1}, x_{2}, x_{3}\right) \cdot x_{j} \mathrm{~d} A$ are the moment of the damaged area with respect to the $x_{i}$ centroidal principal axes (initially, for undamaged cross-section, it is equal to zero), $I_{i i}\left(x_{3}\right)=\int_{A} f\left(x_{1}, x_{2}, x_{3}\right) \cdot x_{j}^{2} \mathrm{~d} A$ are the moment of inertia of the damaged cross-section corresponding to the same principal axes $x_{i}$ and $I_{i j}\left(x_{3}\right)=\int_{A} f\left(x_{1}, x_{2}, x_{3}\right) \cdot\left(x_{j} \cdot x_{i}\right) \mathrm{d} A$ are the inertia products of the damaged cross-section with respect to the same principal axes $\left(x_{i}, x_{j}\right)$. Notice that the principal inertia axes at certain time instant of the process can change their position in a next instant due to the damage of the cross-section of the beam; consequently the inertia products of the damaged cross-section respecting the changed axes can be different than zero.

\subsection{Numerical evaluation of the moment of inertia of the damaged cross-section}

Due to the difficulties in performing a closed form integration of the non-linear equation (12) using the non-linear damage function defined by Eq. (11), the inertia tensor and the area of the damaged cross-section is calculated by means of a numerical algorithm (see Box 2). It is important to note that the selected integration algorithm requires considering that 


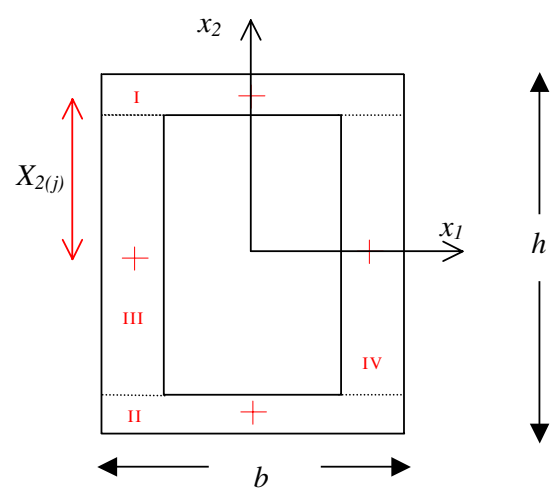

Fig. 4. Subsections of a box cross-section.

one of the points at which the function to be integrated is located is on the border of the cross-section, allowing to capture appropriately the evolution of the damage.

When the cross-section of the pier to be analyzed has a rectangular shape, the described procedure is applied directly. However, if the piers have a box shape, the moment of inertia of the damaged cross-section is obtained by dividing the element into four subsections, as shown in Fig. 4. For each subsection, the damaged area, $A\left(x_{3}\right)_{(\mathrm{J})}$, is

$$
A\left(x_{3}\right)_{(J)}=\int_{A_{(J)}} f\left(x_{1}, x_{2}, x_{3}\right) \mathrm{d} A
$$

and the distance between the neutral axes of each sub cross-section and the global neutral axis of the complete cross-section
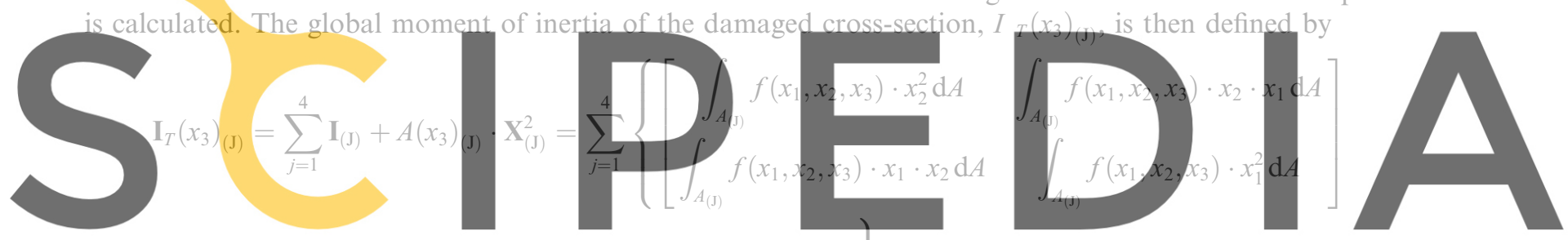

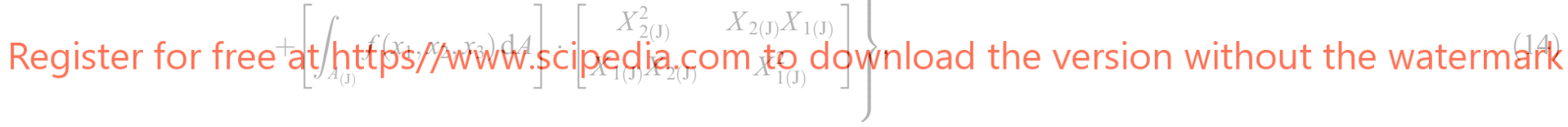

where $\mathbf{I}_{(\mathbf{J})}$ is the moment of inertia of the damaged subsection $j$, evaluated by means of Eq. (14), $A_{(\mathbf{J})}$ is the damaged area of the subsection $j$ and $X_{(\mathrm{J})}^{2}$ are the distances between the neutral axis of the subsections and the global neutral axis of the whole cross-section, which depend on the damage at the cross-section. In Eqs. (13) and (14), the numerical integration has been carried out following its classical form

$$
\begin{aligned}
& A\left(x_{3}\right)_{(\mathrm{J})}=\int_{A_{(\mathrm{J})}} f\left(x_{1}, x_{2}, x_{3}\right) \cdot \mathrm{d} A=J_{\mathrm{acob}} \cdot\left[\sum_{p=1}^{n} \sum_{q=1}^{n} w_{p} \cdot w_{q}\left[f\left(\xi_{1}, \xi_{2}, x_{3}\right)\right]\right]_{(\mathrm{J})}, \\
& m_{i}\left(x_{3}\right)_{(\mathrm{J})}=\int_{A_{(\mathrm{J})}} f\left(x_{1}, x_{2}, x_{3}\right) \cdot x_{j} \mathrm{~d} A=J_{\mathrm{acob}} \cdot\left[\sum_{p=1}^{n} \sum_{q=1}^{n} w_{p} \cdot w_{q}\left[f\left(\xi_{1}, \xi_{2}, x_{3}\right) \cdot \xi_{j}\right]\right]_{(\mathrm{J})} \\
& I_{i i}\left(x_{3}\right)_{(\mathrm{J})}=\int_{A_{(\mathrm{J})}} f\left(x_{1}, x_{2}, x_{3}\right) \cdot x_{j}^{2} \mathrm{~d} A=J_{\mathrm{acob}} \cdot\left[\sum_{p=1}^{n} \sum_{q=1}^{n} w_{p} \cdot w_{q}\left[f\left(\xi_{1}, \xi_{2}, x_{3}\right) \cdot \xi_{j}^{2}\right]\right]_{(\mathrm{J})}, \\
& I_{i j}\left(x_{3}\right)_{(\mathrm{J})}=\int_{A_{(\mathrm{J})}} f\left(x_{1}, x_{2}, x_{3}\right) \cdot x_{j} \cdot x_{i} \mathrm{~d} A=J_{\mathrm{acob}} \cdot\left[\sum_{p=1}^{n} \sum_{q=1}^{n} w_{p} \cdot w_{q}\left[f\left(\xi_{1}, \xi_{2}, x_{3}\right) \cdot \xi_{j} \cdot \xi_{i}\right]\right]_{(\mathrm{J})},
\end{aligned}
$$

where $J_{\mathrm{acob}}$ is the determinant of the gradient of the strains, $w_{p}$ and $w_{q}$ are the numerical weight coefficients, $\xi_{1}$ and $\xi_{2}$ are the isoperimetric normalized coordinates and $n$ is the order of the quadrature of the numerical integration [39]. Particularly, when damage occurs due to the external load, the position of the neutral axis of each subsection is modified according to the area of the subsection that is damaged. This modification must be reflected in the calculation of the distances to the global neutral axis of each subsection. Thus, to obtain each $X_{(\mathrm{J})}^{2}$, it is necessary to know the coordinates $X_{1(\mathrm{~J})}$ and $X_{2(\mathrm{~J})}$ for each subsection, which are evaluated in a general form by means of the following equations: 


$$
X_{1(\mathrm{~J})}=\left[\frac{\int_{A_{(\mathrm{J})}} x_{1} f\left(x_{1}, x_{2}, x_{3}\right) \mathrm{d} A}{\int_{A_{(\mathrm{J})}} f\left(x_{1}, x_{2}, x_{3}\right) \mathrm{d} A}\right] ; \quad X_{2(\mathrm{~J})}=\left[\frac{\int_{A_{(\mathrm{J})}} x_{2} f\left(x_{1}, x_{2}, x_{3}\right) \mathrm{d} A}{\int_{A_{(\mathrm{J})}} f\left(x_{1}, x_{2}, x_{3}\right) \mathrm{d} A}\right] .
$$

\subsection{Linearization of the unbalanced equilibrium equation}

Linearizing Eq. (10) and using the Newton-Raphson procedure, the cross-section equilibrium equation is solved by successive iterations, increasing the curvature and axial strain of the pier in the corresponding cross-section. For this purpose, the generalized strains (axial strain and bending moment) at increment $(n+1)$ and instant $(t+\Delta t)$ is written by means of Taylor series, truncated at its first term, and then forced to zero

$$
\begin{aligned}
\mathbf{0}= & { }^{n+1} \Delta \hat{\boldsymbol{\sigma}}^{t+\Delta t}\left(x_{3}\right) \cong{ }^{n} \Delta \hat{\boldsymbol{\sigma}}^{t+\Delta t}\left(x_{3}\right)+\frac{\partial\left[{ }^{n} \Delta \hat{\boldsymbol{\sigma}}^{t+\Delta t}\left(x_{3}\right)\right]}{\partial \hat{\boldsymbol{\varepsilon}}} \cdot{ }^{n+1} \Delta \hat{\boldsymbol{\varepsilon}}^{t+\Delta t}\left(x_{3}\right)+\cdots \\
\Rightarrow & { }^{n+1} \Delta \hat{\boldsymbol{\varepsilon}}^{t+\Delta t}\left(x_{3}\right)=-\left[{ }^{n} \mathbf{J}^{n+1}\right]^{-1} \Delta \hat{\boldsymbol{\sigma}}^{t+\Delta t}\left(x_{3}\right) \Rightarrow{ }^{n+1} \hat{\boldsymbol{\varepsilon}}^{t+\Delta t}\left(x_{3}\right)={ }^{n} \hat{\boldsymbol{\varepsilon}}^{t+\Delta t}\left(x_{3}\right)+{ }^{n+1} \Delta \hat{\boldsymbol{\varepsilon}}^{t+\Delta t}\left(x_{3}\right) \\
& { }^{n+1} \Delta \sigma^{t+\Delta t}\left(x_{1}, x_{2}, x_{3}\right)=E^{0}\left(x_{1}, x_{2}, x_{3}\right) \cdot{ }^{n+1} \mathbf{x}^{T} \cdot \Delta \hat{\boldsymbol{\varepsilon}}^{t+\Delta t}\left(x_{3}\right) \Rightarrow{ }^{n+1} \sigma^{t+\Delta t}={ }^{n} \sigma^{t+\Delta t}+{ }^{n+1} \Delta \sigma^{t+\Delta t}
\end{aligned}
$$

being

$$
{ }^{n} J^{n+1}=\frac{\partial\left[{ }^{n} \Delta \hat{\boldsymbol{\sigma}}^{t+\Delta t}\left(x_{3}\right)\right]}{\partial \hat{\boldsymbol{\varepsilon}}}=E^{0} \cdot\left[\begin{array}{ccc}
A\left(x_{3}\right) & m_{1}\left(x_{3}\right) & m_{2}\left(x_{3}\right) \\
m_{1}\left(x_{3}\right) & I_{11}\left(x_{3}\right) & I_{12}\left(x_{3}\right) \\
m_{2}\left(x_{3}\right) & I_{21}\left(x_{3}\right) & I_{22}\left(x_{3}\right)
\end{array}\right]
$$

the Jacobian matrix.

For each time increment in which the predictor moment produces an unbalanced load increment greater than an adopted tolerance (Eqs. (17) and (18)), the procedure considers an increment of the curvature in order to obtain a corrector of generalized stresses which permits to reach the equilibrium state. The convergence criterion used states that the stable response is obtained for the cross-section if

$$
\sqrt{\frac{\sum_{i} \Delta \hat{\sigma}_{i}^{2}}{\sum_{i}\left(\hat{\sigma}_{i}^{0}\right)^{2}}} \leqslant \text { TOL }
$$

where TOL is the tolerance adopted $(\mathrm{TOL} \rightarrow 0)$.

\section{Numerical example: Validation of the dynamic model}

The Warth Bridge is located $63 \mathrm{~km}$ far from Vienna, Austria, was built 30 years ago and has two spans of the deck of $62.0 \mathrm{~m}$ and five of $67.0 \mathrm{~m}$, with a total length of $459.0 \mathrm{~m}$. The seven spans of the bridge give rise to six piers with heights of $31.0 \mathrm{~m}, 39.0 \mathrm{~m}, 37.0 \mathrm{~m}, 36.0 \mathrm{~m}, 30.0 \mathrm{~m}$ and $17.6 \mathrm{~m}$, as it can be observed in Fig. 5 .

The geometrical and mechanical properties of the structure of Warth Bridge were obtained from the original design drawings [35]. Thus, the simple compression strength of the concrete is $f_{\mathrm{cu}}^{-}=45.0 \mathrm{MPa}$ for girders and $f_{\mathrm{cu}}^{-}=43.0 \mathrm{MPa}$ for piers. The weight density and Poisson modulus of the concrete are $\gamma=24.0 \mathrm{kN} / \mathrm{m}^{3}$ and $v=0.2$, respectively. In order to consider the weight of the non-structural components, the value of the weight density of the girders was increased to a value of $\gamma=28.0 \mathrm{kN} / \mathrm{m}^{3}$. For the reinforcement bars, $\gamma=78.5 \mathrm{kN} / \mathrm{m}^{3}, v=0.3$ and $E_{\mathrm{s}}=2.0 \times 10^{5} \mathrm{MPa}$ were considered.

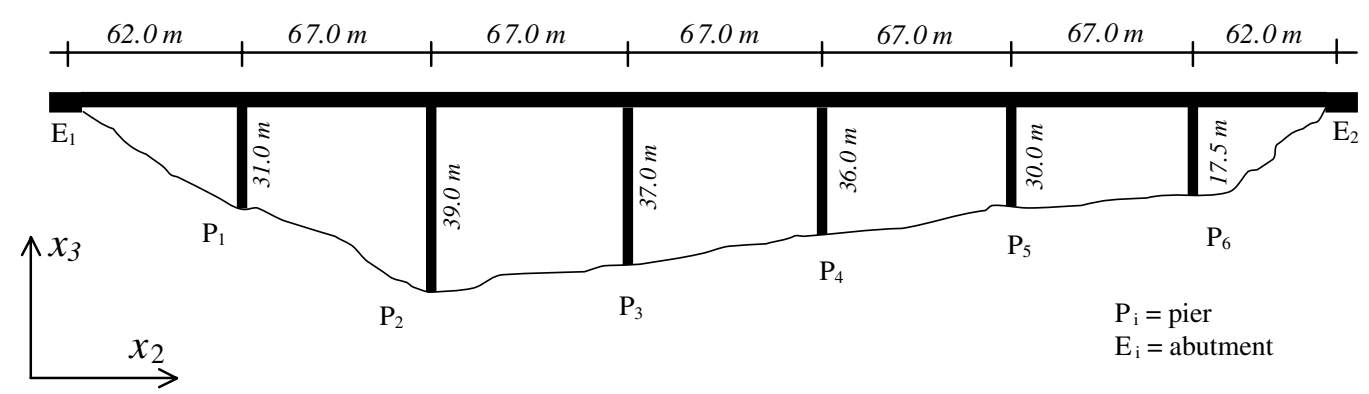

Fig. 5. Elevation of the Warth Bridge, Austria. 
Table 1

Frequencies and periods corresponding to the first six modes of vibration of Warth Bridge

\begin{tabular}{llll}
\hline Mode number & Period $(\mathrm{s})$ & & \\
\cline { 2 - 4 } & Experimental & FE model & Simplified model \\
\hline 1 & 1.25 & 1.18 & 0.94 \\
2 & 0.91 & 0.93 & 0.78 \\
3 & 0.62 & 0.67 & 0.71 \\
4 & 0.45 & 0.52 & 0.60 \\
5 & 0.34 & 0.39 & 0.33 \\
\hline
\end{tabular}

The elastic modulus of the reinforced concrete, $E_{\mathrm{c}}$, was obtained using the mixing theory $[5,13,28]$, which determines the properties of the elements composed of more than one material. In particular, the elastic modulus of the reinforced concrete was determined by means of the following expressions:

$$
E_{\mathrm{c}}=k_{\mathrm{h}} E_{\mathrm{h}}+k_{\mathrm{a}} E_{\mathrm{a}}
$$

where in this case

$$
k_{\mathrm{h}}=\frac{A_{\mathrm{h}}}{A}, \quad k_{\mathrm{a}}=\frac{A_{\mathrm{a}}}{A}
$$

and $E_{\mathrm{h}}, E_{\mathrm{a}}$ and $E_{\mathrm{c}}$ are the Young's modulus of the concrete, longitudinal reinforcement, and composite material, respectively, and $A_{\mathrm{h}}, A_{\mathrm{a}}$, and $A$ are the corresponding areas. In Eq. (19) a value $E_{\mathrm{h}}=2.8 \mathrm{E} 04 \mathrm{MPa}$ was supposed.

The experimental results obtained by ÖFPZ-ARSENAL Institute $[9,11]$ for Warth Bridge show that the first six modes of vibration of the structure (see the first column of Table 1) correspond to the direction transversal to the bridge axis. It can be seen that the experimental periods are similar to the transversal periods obtained with the finite element model (column 2 of Table 1) and to those calculated with the proposed model (column 3 of Table 1).

The finite element model was developed using the ABAQUS (1999) code [1], using eight Timoshenko-beam elements to represent the girders and piers and two elements for the foundations (totally 116 elements). Box beams with equivalent elastic properties have been used for the girders. Pin elements were used for the pier-girder connection zone. The following constraints were considered: (1) the three translational degrees of freedom were fixed and the rotations released at the connexion zone with the abutments; (2) the connections between piers and girders assured the continuity in translation and fixed the rotation; and (3) the foundation of the piers was supposed to lean on a rigid base. Thus, the soil-structure interaction effect was not considered.

\section{Numerical example: Quasi-static analysis of the Warth Bridge pier model tested at JCR, ISPRA, Italy}

In this section, the numerical simulation of the quasi-static structural behavior of shorter pier of the Warth Bridge is given (identified as P6 in the Fig. 5). This pier was studied experimentally in the JCR Ispra Laboratory, Italy [35] and numerically, using a finite elements approach, by Faria et al. [10]. The top of this $5.75 \mathrm{~m}$ high pier has been subjected to a horizontal quasi-static load. The seismic behavior of the pier has been evaluated using the described Bernoulli beam formulation extended to the non-linear case of Kachanov damage [15,22]. That is, without using the finite element approach, it has been introduced within the frame of the classical theory of Bernoulli a non-linear continuum damage model. This formulation allows for the evaluation of the structural behavior in the non-linear field with a very low computational cost and the obtained results are similar to the experimental and to the finite element results. This model leads to a good, low computational cost, non-linear solution required by the evaluation of the seismic vulnerability of the bridge, requiring multiple structural dynamic response calculations. The objective of the structural solution developed in this paper in not only a good prediction of the load-displacement relationship, but also a good evaluation of the cross-sectional damage.

The mechanical properties of the reinforced concrete bridge pier are calculated using the mixing theory [5,28], which combines the mechanical behavior of the concrete and steel. The behavior of the concrete is represented by means of a damage model described in Appendix A and the behavior of the steel is represented by means of an anisotropic perfect elasto-plastic model [25]. This combination of the concrete and steel behaviors given by the mixing theory uses the following plastic-damage constitutive equation at each point of the composite material:

$$
\boldsymbol{\sigma}\left(d, \boldsymbol{\varepsilon}^{\mathrm{p}}\right)=k_{\mathrm{c}} \boldsymbol{\sigma}_{\mathrm{c}}(d)+k_{\mathrm{s}} \boldsymbol{\sigma}_{\mathrm{s}}\left(\boldsymbol{\varepsilon}^{\mathrm{p}}\right)=k_{\mathrm{c}}\left[(1-d)\left(\mathrm{C}_{0}\right)_{\mathrm{c}}: \boldsymbol{\varepsilon}\right]+k_{\mathrm{s}}\left[\left(\mathrm{C}_{0}\right)_{\mathrm{s}}:\left(\boldsymbol{\varepsilon}-\boldsymbol{\varepsilon}_{\mathrm{s}}^{\mathrm{p}}\right)\right]
$$

being: $\boldsymbol{\sigma}, \boldsymbol{\sigma}_{\mathrm{c}}(d), \boldsymbol{\sigma}_{\mathrm{s}}\left(\varepsilon^{\mathrm{p}}\right)$, the stresses in the composite material, in the damaged concrete and in the plastic steel, respectively. $\left(\mathrm{C}_{0}\right)_{\mathrm{c}}$ and $\left(\mathrm{C}_{0}\right)_{\mathrm{s}}$ are, respectively, the initial constitutive tensors in the concrete and steel while $k_{\mathrm{c}}=A_{\mathrm{c}}(d) /\left[A_{\mathrm{c}}(d)+A_{\mathrm{s}}\right]$ and 
$k_{\mathrm{s}}=A_{\mathrm{s}} /\left[A_{\mathrm{c}}(d)+A_{\mathrm{s}}\right]$ are the relative areas corresponding to each material of the cross-section of the pier. The characteristics of the materials used are given in Table 2.

The initial values at the clamped cross-section, corresponding to the initial, non-damaged state, are the following:

$$
\begin{aligned}
& \left(A_{\mathrm{c}}\right)_{0}=0.6579 \mathrm{~m}^{2}, \quad\left(A_{\mathrm{s}}\right)_{0}=76.77 \times 10^{-4} \mathrm{~m}^{2} \Rightarrow\left\{\begin{array}{l}
\left(k_{\mathrm{c}}\right)_{0}=0.9884, \\
\left(k_{\mathrm{s}}\right)_{0}=0.011533,
\end{array}\right. \\
& (E)_{0}=\left(k_{\mathrm{c}}\right)_{0}\left(E_{\mathrm{c}}\right)_{0}+\left(k_{\mathrm{s}}\right)_{0} E_{\mathrm{s}}=35.418 \mathrm{MPa} \text {, } \\
& \left.\begin{array}{l}
\left(f_{y}^{+}\right)_{0}=\left(k_{\mathrm{c}}\right)_{0}\left(f_{\mathrm{c} y}^{+}\right)_{0}+\left(k_{\mathrm{s}}\right)_{0}\left(f_{\mathrm{s} y}^{+}\right)_{0}=9.984 \mathrm{MPa} \\
\left(f_{y}^{-}\right)_{0}=\left(k_{\mathrm{c}}\right)_{0}\left(f_{\mathrm{c} y}^{-}\right)_{0}+\left(k_{\mathrm{s}}\right)_{0}\left(f_{\mathrm{s} y}^{-}\right)_{0}=49.421 \mathrm{MPa}
\end{array}\right\} n_{\mathrm{r}}=\frac{\left(f_{y}^{-}\right)_{0}}{\left(f_{y}^{+}\right)_{0}}=4.95 .
\end{aligned}
$$

Fig. 6 shows the geometric characteristics and boundary condition for pier P6.

In the proposed model, the pier is represented by a single beam. In this example, the moment-curvature is evaluated in 10 points along $x_{3}$-axis. In each of the $x_{3}$ points, six Gauss points per each of the subsections of Fig. 4 (totally 24 Gauss points) are located on the cross-section of the beam.

The pier is considered perfectly clamped to the foundation and the following sequence of loads is applied at its upper end:

1. A compression axial load of $3820.00 \mathrm{kN}$.

2. Once applied this load, three horizontal displacements are applied sequentially.

Table 2

Properties of the materials compounding the reinforced concrete

\begin{tabular}{lll}
\hline Mechanical properties & Steel & Concrete \\
\hline Young's modulus & $E_{\mathrm{s}}=200.00 \mathrm{GPa}$ & $E_{\mathrm{c}}=33.50 \mathrm{GPa}$ \\
Compression strength at the elastic limit & $f_{\mathrm{s} y}^{-}=545.00 \mathrm{MPa}$ & $f_{\mathrm{cy}}^{-}=20.00 \mathrm{MPa}$ \\
Maximum compression strength & $f_{\mathrm{s} u}^{-}=600.00 \mathrm{MPa}$ & $f_{\mathrm{cu}}^{-}=43.00 \mathrm{MPa}$ \\
Tension strength at the elastic limit & $f_{\mathrm{s} y}^{+}=545.00 \mathrm{MPa}$ & $f_{\mathrm{cy}}^{+}=3.10 \mathrm{MPa}$ \\
Maximum tension strength & $f_{\mathrm{s} u}^{+}=600.00 \mathrm{MPa}$ & $f_{\mathrm{cy}}^{+}=3.10 \mathrm{MPa}$ \\
Fracture energy & $\left(G_{\mathrm{f}}\right)_{\mathrm{s}}=12,000.00 \mathrm{MN} / \mathrm{m}$ & $\left(G_{\mathrm{f}}\right)_{\mathrm{s}}=1.20 \mathrm{MN} / \mathrm{m}$ \\
\hline
\end{tabular}
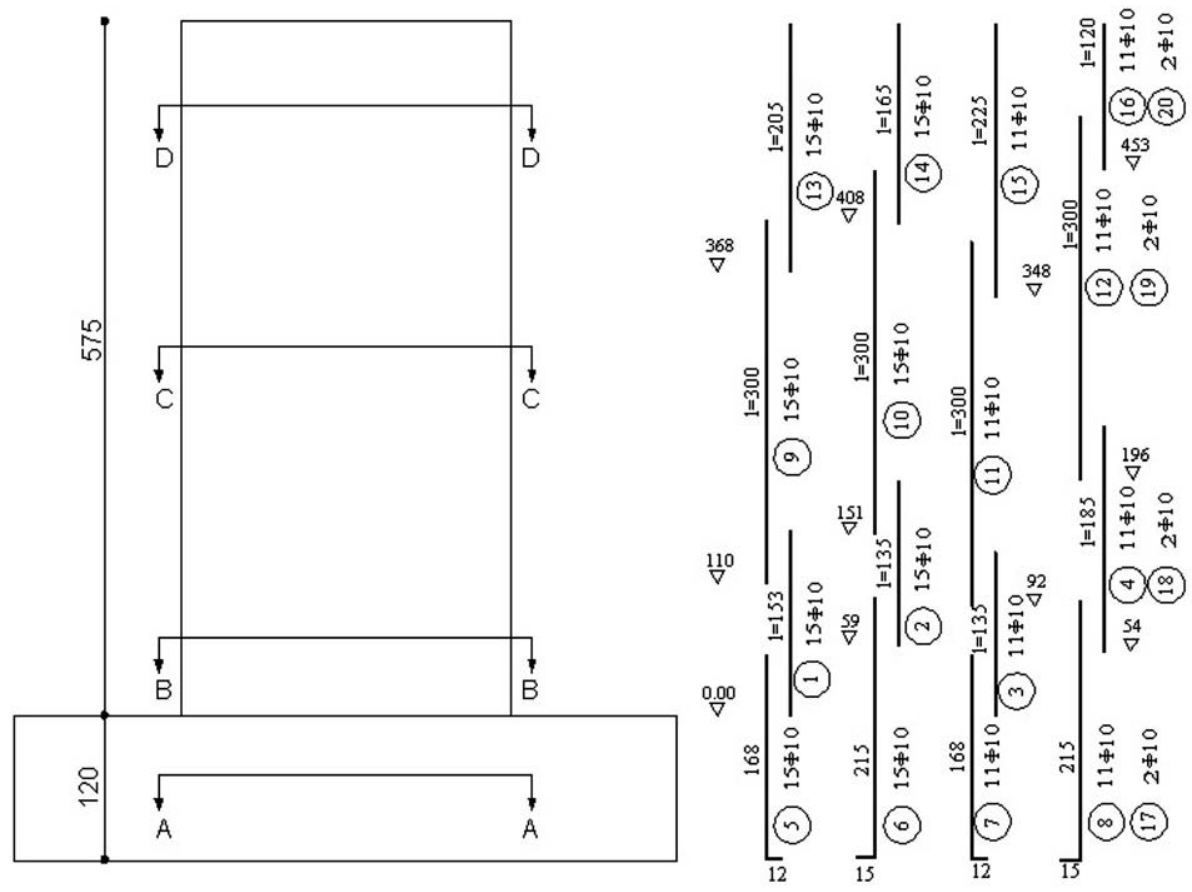

Fig. 6. Geometry and reinforcement description of pier P6 belonging to Warth Bridge [35]. 
(1) $-0.026 \mathrm{~m} \leqslant u_{\mathrm{h}} \leqslant+0.026 \mathrm{~m}$.

(2) $-0.055 \mathrm{~m} \leqslant u_{\mathrm{h}} \leqslant+0.055 \mathrm{~m}$.

(3) $-0.1 \mathrm{~m} \leqslant u_{\mathrm{h}} \leqslant+0.1 \mathrm{~m}$.

These cycles of displacements introduce degradation on the clamped cross section of the pier and the numerical results obtained in this paper (Fig. 7b) are compared with those obtained by Faria et al. [10] and in the JCR Ispra laboratory [35] (see Fig. 7a).

From the results obtained in the present work by using the damage model and the described structural approach, a reasonable solution is obtained and it is adequate to the main objective of the paper which is the development of fragility curves. In spite of the simplicity of the model, the results, in their general features, reach similar values than those obtained experimentally and numerically through FEM models with two internal damage variables (damage variable for compression and tension). Nevertheless, the most important aspect is the very low computational cost that encourages to its application in solving multiple analysis problems like Monte Carlo simulations [14]. The most important differences between the two graphs of Fig. 7 can be observed in the unloading branch, because in this case the recovery of the material properties during the change of the sign of the load is evaluated using a simple constitutive model with a single damage index. Remember that it is an intrinsic characteristic of the isotropic damage constitutive model that the unloading-reloading curves always cross the origin of the coordinate axes. Moreover, according to the principal hypotheses made, the proposed model is unable to take into account neither the sliding of the steel bars nor the Bauschinger cyclic effect. In Fig. 8, the top
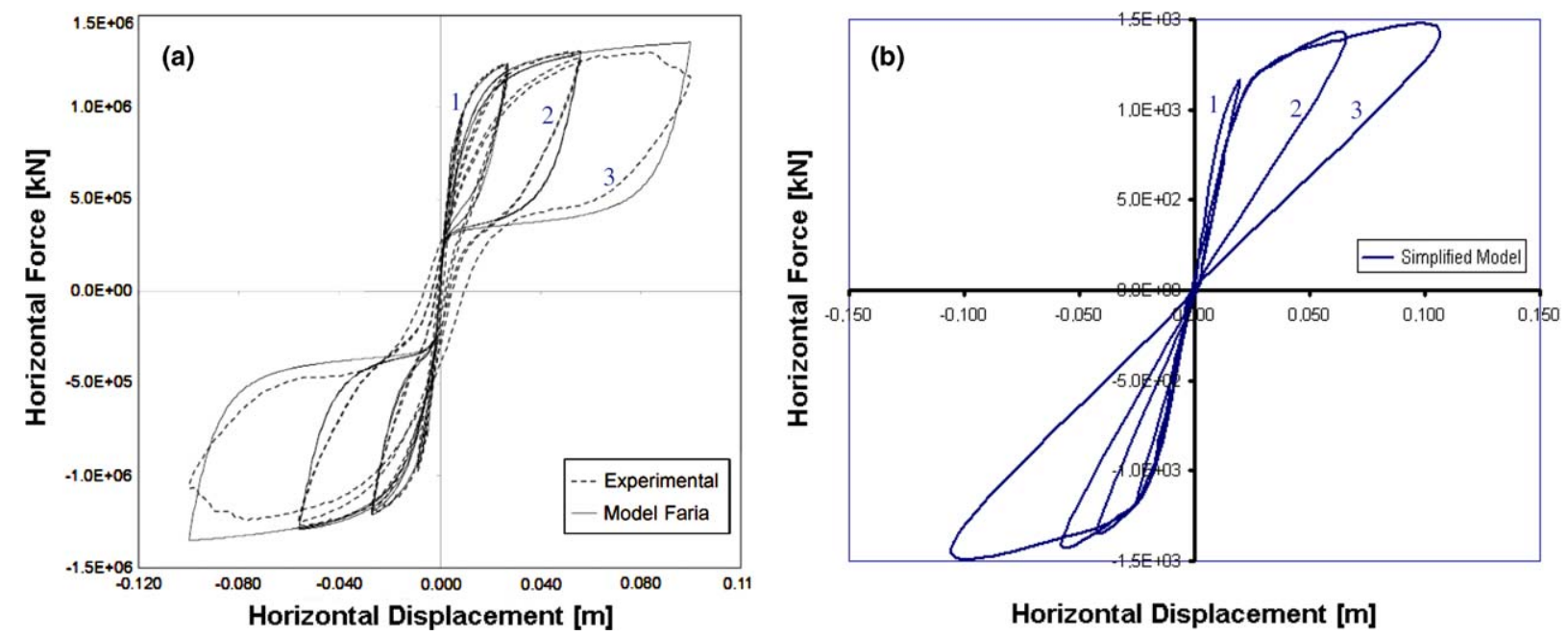

Horizontal Displacement [m]

Fig. 7. Load-displacement behavior in the pier for the load sequences 1, 2 and 3. (a) Experimental results [35] and numeric results [10]. (b) Results obtained in the present work.

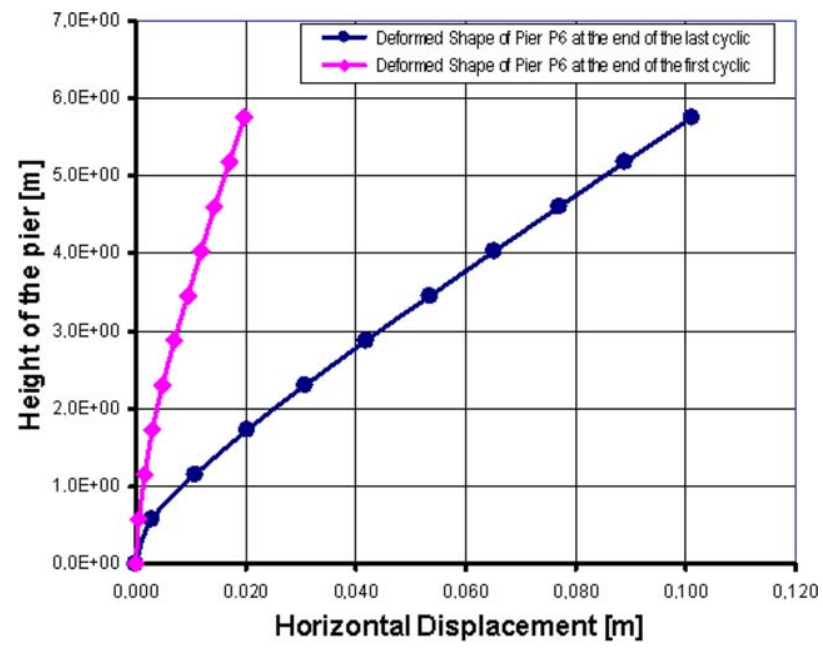

Fig. 8. Displacement of the pier P6 at the end of the first load cycle and at the end of the last load cycle. 

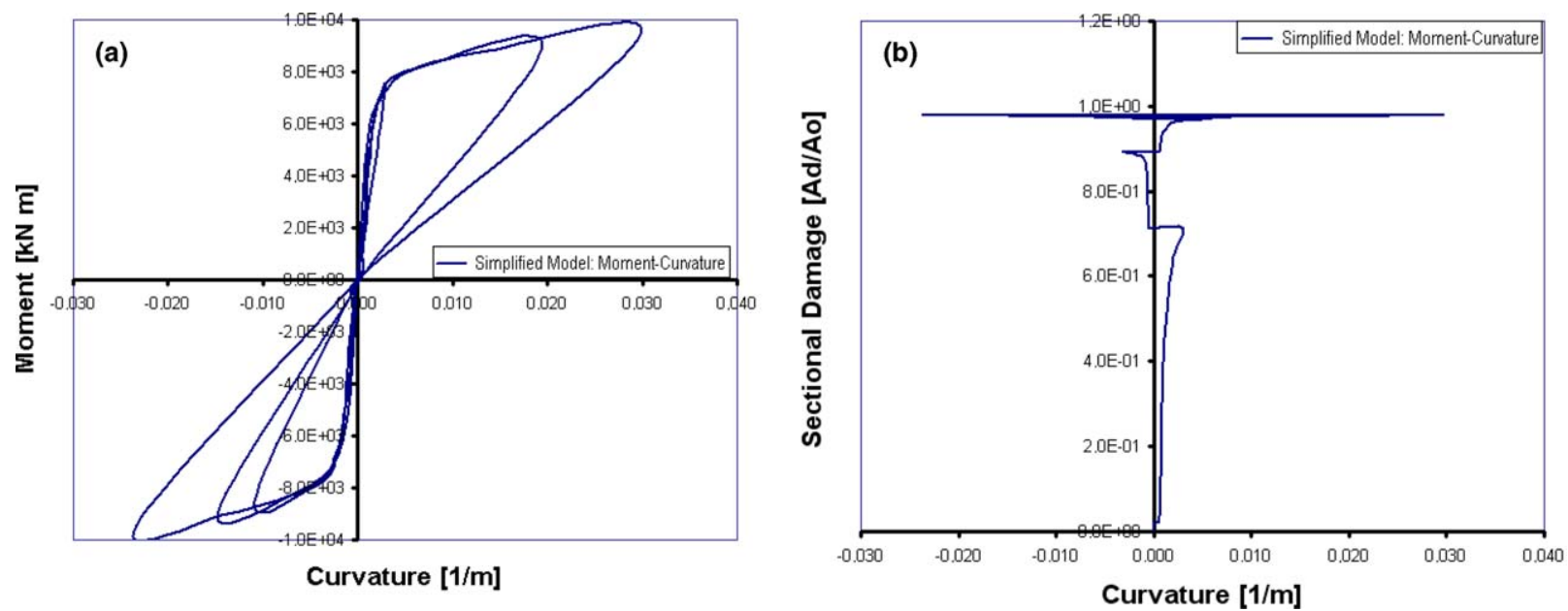

Fig. 9. (a) Moment-curvature evolution at the base section of the pier. (b) Evolution of the damage at the base section of the pier in function of the curvature level.

pier displacement is represented at the end of the load sequence 1 and then, in the same figure, the deformed pier is drawn at the end of the last load sequence 3. In this last case the damaged cross-section is located near the foundation of the pier, while the rest of the cross-sections return to their initial undamaged state (rotation of rigid solid around the kneecap in Fig. 8).

The degradation of the cross-section is shown in Fig. 9. Fig. 9a shows the moment-curvature evolution, and Fig. 9b shows the evolution of the damage index as a function of the curvature. It can be seen in this figure that the level of damage at the end of the process is near to one. This statement signifies the $100 \%$ of the available free energy corresponding to the base cross-section of the pier has been dissipated, according to the second thermodynamic law (see the formulation of Appendix A).

\section{Numerical example: Seismic analysis of Warth Bridge, Austria}

The maximum damage at the base cross-section of a pier is obtained as [27]

$$
D=\frac{M_{\mathrm{e}}\left(x_{3}\right)-M_{\text {int }}\left(x_{3}\right)}{M_{\mathrm{e}}\left(x_{3}\right)} \quad \text { for } x_{3}=0,
$$

which, in this example, is considered equal to the pier damage $D_{i}$. Thus, the mean global structural damage caused by the seismic action in the bridge is calculated as the average of the pier damage indices

$$
D_{m}=\frac{\sum_{i} D_{i}}{n_{\mathrm{p}}} \quad i=1, \ldots, n_{\mathrm{p}},
$$

where $n_{\mathrm{p}}$ is the number of piers of the bridge.

The seismic behavior of Warth Bridge was analyzed as an example of application of the proposed dynamic model. The bridge was designed to resist a horizontal acceleration of $0.04 \mathrm{~g}$, using a quasi-static method. According to the current Austrian seismic code, it is necessary to consider horizontal design accelerations of the order of $0.1 \mathrm{~g}$ for the bridge site [30]. This seismic design acceleration takes into account the recent seismic activity in the zone, where occurred more severe earthquakes than those considered by the previous seismic code. Therefore, a complete study of the structural behavior was necessary to evaluate the safety of the structure during future earthquakes.

Aiming to compare the damage provided by the proposed model with that obtained by means of the FE model, a nonlinear analysis of the Warth Bridge was performed for an action at the base of each pier $a(t)=t \sin (\omega t)$, $\omega$ being the frequency of the input signal, assumed to be similar to the fundamental frequency of each pier. The material properties are the same as in the previous examples. The damage of the FE model has been calculated by implementing in the ABAQUS code [1] the isotropic damage model [24] as an external subroutine. For both models, the maximum damage was obtained at the integration points and their values are shown in Table 3. It can be observed that both models provide similar maximum damages. The non-linear analysis performed by means of the proposed model requires $25 \mathrm{~s}$ of CPU in a Silicon Graphics Origin 2000. The same analysis performed by using the finite element model in the ABAQUS code needs $3.27 \mathrm{~h}$ in the same computer.

The seismic vulnerability of the Warth Bridge was evaluated by developing fragility curves using Monte Carlo simulations. The mechanical parameters considered as random are the following: simple compression and tensile strength, 
Table 3

Maximum damage at the integration points of the piers of the Warth Bridge

\begin{tabular}{lll}
\hline Pier number & FE model & Simplified model \\
\hline 1 & 0.9514 & 1.0000 \\
2 & 0.9842 & 0.9831 \\
3 & 0.9757 & 0.9820 \\
4 & 0.9692 & 0.9844 \\
5 & 0.9497 & 0.9834 \\
6 & 0.8552 & 0.9950 \\
\hline
\end{tabular}

undamaged Young's modulus of the concrete and reinforcement steel for the piers, Young's modulus of the reinforced concrete of the girders, mass density of piers and girders, area of the steel bars of the piers, energy of fracture and shear modulus of the bearings. The values given in the previous examples of each characteristic have been considered as mean values of the random variable. The pier damage index and the mean global damage index were also considered as random output variables.

The statistical relationship between the input and output variables of the problem was obtained using the Monte Carlo simulation. The probabilistic characteristics of the input random variables were defined by using experimental and analytical tests performed in different researches [12]. A marginal distribution function and a correlation coefficient were assigned to each input variable. Given these values, the statistics of the output variables, in particular the principal statistical moments, histograms and accumulated frequency curves, were determined.

For each output variable the best distribution function was selected using the Kolmogorov-Smirnov goodness of fit test for significance levels of 0.01 or 0.05 . Fragility curves have been thus obtained, which represent the accumulated probability for different damage levels.

Warth Bridge is located in a zone of moderate seismicity, for which the number of available real records is insufficient to estimate its seismic vulnerability. Therefore, artificial accelerograms have been developed for each bridge pier, using a onedimensional model for a seismic scenario of magnitude 5.5, depth of $10 \mathrm{~km}$ and distance from the source of $8 \mathrm{~km}$. The records obtained in Ref. [31] were used to determine accelerograms with peak ground accelerations between $0.05 \mathrm{~g}$ and $0.40 \mathrm{~g}$ with an increment of $0.05 \mathrm{~g}$. The maximum value of the peak ground acceleration of $0.40 \mathrm{~g}$ was selected because it is slightly greater than the seismic magnitude of 6.0 , predicted by some authors as the probable maximum magnitude at the bridge site [18].

The fragility curves for the global damage index $D_{m}$, of Warth Bridge are shown in Fig. 9, in which the curves associated with the peak ground accelerations of $0.05 \mathrm{~g}$ and $0.10 \mathrm{~g}$ are not shown due to the fact that for these earthquake sizes the structure has a linear behavior. For all the considered peak ground accelerations, the Gamma theoretical distribution was fitted for the global damage index $D_{m}$. A Monte Carlo simulation considering 500 structural analyses performed in a Silicon Graphics Origin 2000 with eight $300 \mathrm{MHz}$ processors requires $3.5 \mathrm{~h}$. The same analysis, performed in the same computer with the ABAQUS code, requires $166 \mathrm{~h}$.

Using the fragility curves of the bridge, a damage probability matrix is obtained, which provides the occurrence probability of a given damage state if an earthquake having a given ground acceleration occurs (see Table 4).

On the basis of Fig. 10 and the damage probability matrix of Table 4, some results regarding the possible damage to the bridge can be discussed. For example, for the damage index $D_{m}$, the probability of being in the 10-20\% damage interval is 0.47 , when the peak ground acceleration was $0.25 \mathrm{~g}$. It is observed in Fig. 9 that the probability of a damage greater than $50 \%$, which could be associated with irreparable damage, can occur for peak ground accelerations between $0.35 g$ and $0.40 g$. Taking into account that for the maximum design acceleration of $0.1 \mathrm{~g}$, stipulated by the new Austrian seismic code requirements, the response of the structure is practically linear.

Table 4

Damage probability matrix for the global damage index $D_{m}$

\begin{tabular}{|c|c|c|c|c|c|c|}
\hline \multirow[t]{2}{*}{ Damage state $(\%)$} & \multicolumn{6}{|c|}{ Earthquake peak ground acceleration $(\% g)$} \\
\hline & 0.15 & 0.20 & 0.25 & 0.30 & 0.35 & 0.40 \\
\hline 0 & 0.8870 & - & - & - & - & - \\
\hline $0-10$ & 0.1130 & 0.9997 & 0.0148 & - & - & - \\
\hline $20-30$ & - & - & 0.5110 & 0.2941 & 0.0218 & 0.0242 \\
\hline $30-40$ & - & - & 0.0021 & 0.6967 & 0.6322 & 0.4733 \\
\hline $40-50$ & - & - & - & 0.0092 & 0.3385 & 0.4535 \\
\hline
\end{tabular}




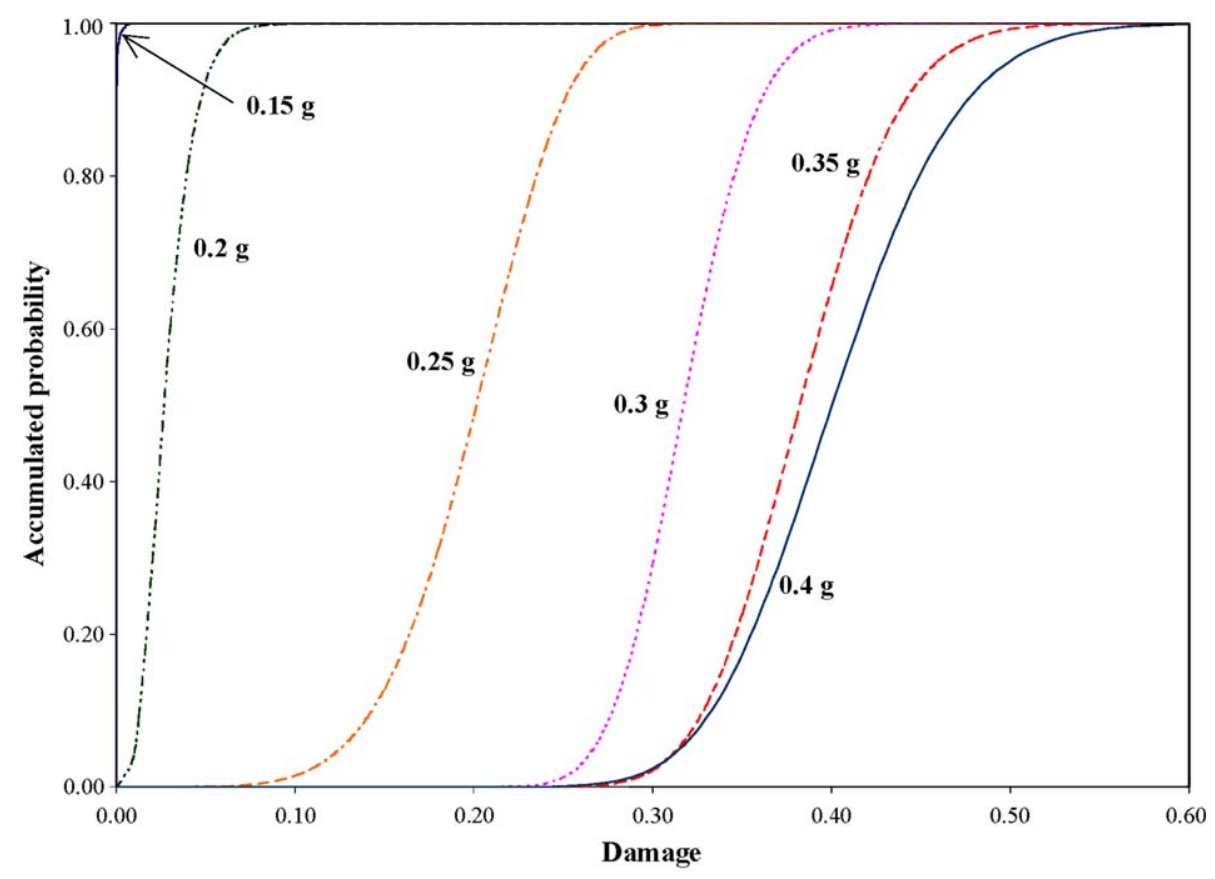

Fig. 10. Fragility curves for the $D_{m}$ global damage index.

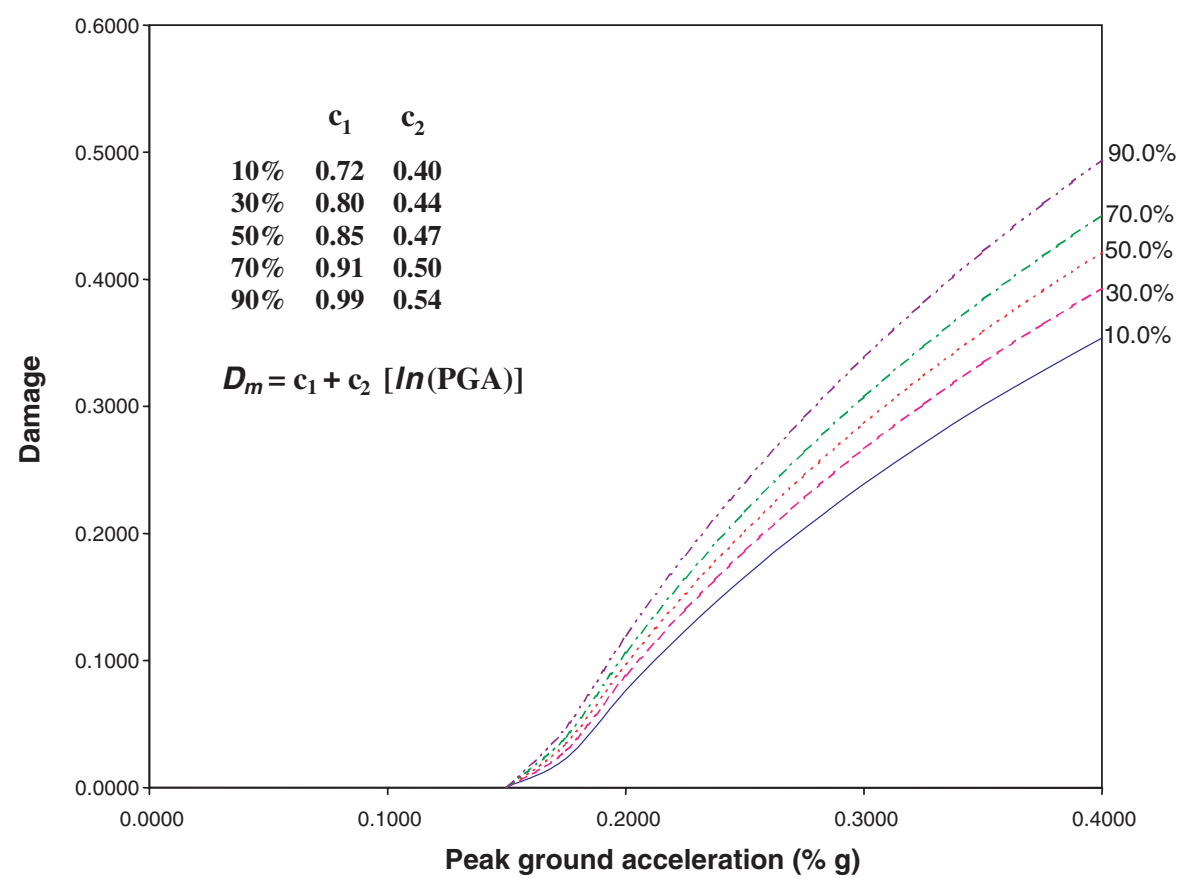

Fig. 11. Earthquake size vs. damage for different probabilities of the global damage index $D_{m}$.

The fragility curves of Fig. 11 relate the global damage with the earthquake size (peak ground acceleration), for different probabilities of occurrence. This curve can be more easily applied in a practical case.

\section{Conclusions}

A procedure to evaluate the seismic vulnerability of RC highway bridges with simple pier bents is developed in this work. It is based on a model of evaluation of the damage caused by a horizontal action in the piers of the bridge. The proposed model considers a single degree of freedom for each pier, namely the transversal displacements at their top. 
The damage of piers due to the seismic action is obtained by using an isotropic damage model based on the Continuum Damage Mechanics, in terms of the moment of inertia of the damaged cross-section at the base of each bridge pier. The proposed simplified model was verified using experimental and FEM results.

The simplified non-linear analysis performed with the proposed model gives satisfactory results similar to those of the laboratory test and the FEM results. On the basis of these results it is concluded that the proposed model suitably describes the maximum damages of the piers of RC bridges, and that it is a low-cost computer tool, ideal for the multi-analysis processes required by the evaluation of seismic vulnerability.

Uncertainties have been considered in the structural and mechanical characteristics of the Warth Bridge, used as an example of application of the proposed model. In the Monte Carlo simulation which has been performed, the proposed model has been used in order to obtain the non-linear seismic response of each one of the 500 samples used in the analysis. The most important results which have been obtained were fragility curves and damage probability matrices, allowing assessing the seismic vulnerability of the bridge. A summary of the results are shown in the paper. The model was very effective in performing this analysis, when compared with the results obtained with a more sophisticated finite element model.

\section{Acknowledgments}

This research was partially supported by the European Commission, Environmental program RTD Project ENV4-CT97-0574 "Advanced Methods for Assessing the Seismic Vulnerability of Bridges (VAB)", Global Change and Ecosystems program integrated project GOCE-CT-2003-505448 "Risk Mitigation for Earthquakes and Landslides (LESSLOSS)", by the Spanish Government (Ministerio de Educación y Ciencia), project REN2002-03365/RIES "Development and application of advanced approaches for the evaluation of the seismic vulnerability and risk of structures (EVASIS)", project BIA2003-08700-C03-02 "Numerical simulation of the seismic behaviour of structures with energy dissipation devices" and by the Spanish Government (Ministerio de Fomento) "Numerical simulation methodology for the reinforced concrete behavior structures reinforced with composite materials". This support is gratefully acknowledged.

\section{Appendix A. Continuum constitutive damage law}

A brief review of the isotropic continuum damage model at a point of a structure is made [24]. The damage at a point of a continuous solid is defined as the degradation of the stiffness and strength due to the decrease of the effective area. The continuum theory of the damage was formulated by Kachanov [15] in the creep behavior context, but later on it has been reformulated and accepted as a valid alternative to simulate the rate independent behavior of several materials [5-7,17,19$21,37,38]$.

Degradation of the material properties occurs due to the presence and growth of small cracks and voids inside the structure of the material. This phenomenon can be simulated by means of the continuum mechanics taking into account a scalar or tensorial internal damage variable. This internal variable of damage measures the level of degradation of the material in a point and its evaluation is based on the transformation of the real stresses in other effective stresses. For the isotropic damage used here, the relationship between the real and the effective stress is described by the damage variable $d$

$$
\boldsymbol{\sigma}_{0}=\frac{\boldsymbol{\sigma}}{(1-d)} .
$$

In this equation, $d$ is the internal variable of damage; $\boldsymbol{\sigma}$ it is the Cauchy stress tensor and $\boldsymbol{\sigma}_{0}$ is the effective stress tensor, evaluated in the "no-damaged" space. This internal variable represents the loss of stiffness level in a point of the material and its upper and lower limits are given by

$$
0 \leqslant d \leqslant 1 \text {. }
$$

The upper limit $(d=1)$ represents the maximum damage in a point and the lower limit $(d=0)$ represents a non-damaged point.

The Helmholtz [22] free energy for the isotropic damage model is given by the expression

$$
\begin{aligned}
& \Psi=\Psi\left(\boldsymbol{\varepsilon} ; p_{i}\right) \quad \text { with } p_{i}=\{d\}, \\
& \Psi=\Psi(\boldsymbol{\varepsilon} ; d)=(1-d) \Psi_{0}(\boldsymbol{\varepsilon}) .
\end{aligned}
$$

The elastic part of the free energy, in the small strain case, can be written in the following quadratic form:

$$
\Psi_{0}(\boldsymbol{\varepsilon})=\frac{1}{2} \varepsilon: C_{0}: \varepsilon
$$


where $C_{0}$ is the elastic undamaged constitutive tensor. The mechanical part of the dissipation, for uncoupled thermal problem, can be written by using the Clausius-Plank inequality [22]

$$
\Xi=\left(\boldsymbol{\sigma}-\frac{\partial \Psi}{\partial \boldsymbol{\varepsilon}}\right): \dot{\boldsymbol{\varepsilon}}-\frac{\partial \Psi}{\partial d} \dot{d} \geqslant 0 .
$$

Applying the Coleman method [22] to the dissipative power (Eq. (A.5)) the following constitutive equation and dissipative inequality are obtained for each point of the material

$$
\begin{aligned}
& \boldsymbol{\sigma}=\frac{\partial \Psi}{\partial \boldsymbol{\varepsilon}}=(1-d) \frac{\partial \Psi_{0}}{\partial \boldsymbol{\varepsilon}}=(1-d) \mathrm{C}_{0}: \boldsymbol{\varepsilon} \\
& \Xi=\Psi_{0} \dot{d} \geqslant 0 .
\end{aligned}
$$

This approach defines the beginning of the non-linear behavior in each point of the solid and it can be defined by using the plasticity theory

$$
\overline{\mathbf{F}}\left(\boldsymbol{\sigma}_{0} ; \mathbf{q}\right)=f\left(\boldsymbol{\sigma}_{0}\right)-c(d) \leqslant 0, \quad \text { with } \mathbf{q} \equiv\{d\},
$$

where $f\left(\boldsymbol{\sigma}_{0}\right)$ is a scalar function of the stress tensor $\boldsymbol{\sigma}_{0}=\mathrm{C}_{0}: \boldsymbol{\varepsilon}$ and $c(d)$ is the strength threshold of damage. The initial value of damage is set up on $c\left(d^{0}\right)=c^{\max }=\sigma^{\max }$ and represents the uniaxial strength at crushing state. The damage process begins when $f\left(\boldsymbol{\sigma}_{0}\right)$ is greater than $c^{\max }=\sigma^{\max }$. Eq. (A.8) can be written in a more general form throughout the following equivalent expression:

$$
\overline{\mathrm{F}}\left(\boldsymbol{\sigma}_{0} ; \mathbf{q}\right)=G\left[f\left(\boldsymbol{\sigma}_{0}\right)\right]-G[c(d)] \leqslant 0, \quad \text { with } \mathbf{q} \equiv\{d\},
$$

where $G[\chi]$ is a monotonic scalar function, invertible and positive with positives derivative.

The evolution law for the internal damage variable can be written in the following general form:

$$
\dot{d}=\dot{\mu} \frac{\partial \overline{\mathrm{F}}\left(\boldsymbol{\sigma}_{0} ; \mathbf{q}\right)}{\partial\left[f\left(\boldsymbol{\sigma}_{0}\right)\right]} \equiv \dot{\mu} \frac{\partial G\left[f\left(\boldsymbol{\sigma}_{0}\right)\right]}{\partial\left[f\left(\boldsymbol{\sigma}_{0}\right)\right]},
$$

where $\mu$ is a non-negative scalar value named damage consistency parameter, whose definition is close to the plastic consistency parameter $\lambda$. As in the plasticity theory, the evaluation of this parameter is made using the Ilyushin consistency condition [22]. From this condition, and from the properties of $G[\chi]$, the following function is obtained:

$$
\overline{\mathrm{F}}\left(\boldsymbol{\sigma}_{0} ; \mathbf{q}\right)=0 \Rightarrow G\left[f\left(\boldsymbol{\sigma}_{0}\right)\right]=G[c(d)] \Rightarrow f\left(\boldsymbol{\sigma}_{0}\right)=c(d) \Rightarrow \frac{\partial G\left[f\left(\boldsymbol{\sigma}_{0}\right)\right]}{\partial f\left(\boldsymbol{\sigma}_{0}\right)}=\frac{\partial G[c(d)]}{\partial c(d)}
$$

and, from here, the permanency condition is deduced

$$
\dot{\overline{\mathrm{F}}}\left(\boldsymbol{\sigma}_{0} ; \mathbf{q}\right)=0 \Rightarrow \frac{\partial G\left[f\left(\boldsymbol{\sigma}_{0}\right)\right]}{\partial f\left(\boldsymbol{\sigma}_{0}\right)} \dot{f}\left(\boldsymbol{\sigma}_{0}\right)-\frac{\partial G[c(d)]}{\partial c(d)} \dot{c}(d)=0 \Rightarrow \dot{f}\left(\boldsymbol{\sigma}_{0}\right)=\dot{c}(d) .
$$

Observing the rate of the threshold damage function $\partial G\left[f\left(\boldsymbol{\sigma}_{0}\right)\right] / \partial t=\dot{G}\left[f\left(\boldsymbol{\sigma}_{0}\right)\right]$ (Eq. (A.12)) and comparing with the evolution law of the internal variable $\dot{d}$ (Eq. (A.10)), the following expression for the damage consistency parameter is obtained:

$$
\left.\begin{array}{l}
\dot{G}\left[f\left(\boldsymbol{\sigma}_{0}\right)\right]=\frac{\partial G\left[f\left(\boldsymbol{\sigma}_{0}\right)\right]}{\partial f\left(\boldsymbol{\sigma}_{0}\right)} \dot{f}\left(\boldsymbol{\sigma}_{0}\right) \\
\dot{d}=\dot{\mu} \frac{\partial G\left[f\left(\boldsymbol{\sigma}_{0}\right)\right]}{\partial\left[f\left(\boldsymbol{\sigma}_{0}\right)\right]}
\end{array}\right\} \Rightarrow \dot{d} \equiv \dot{G}\left[f\left(\boldsymbol{\sigma}_{0}\right)\right] \Rightarrow \dot{\mu} \equiv \dot{f}\left(\boldsymbol{\sigma}_{0}\right)=\dot{c}(d)=\frac{\partial f\left(\boldsymbol{\sigma}_{0}\right)}{\partial \boldsymbol{\sigma}_{0}}: \dot{\boldsymbol{\sigma}}_{0}=\frac{\partial f\left(\boldsymbol{\sigma}_{0}\right)}{\partial \boldsymbol{\sigma}_{0}}: \mathrm{C}_{0}: \dot{\boldsymbol{\varepsilon}} .
$$

Time integration over the rate of internal damage variable (Eq. (A.13)) gives the following explicit expression for the damage evaluation in each point of the solid:

$$
d=\int_{t} \dot{d} \mathrm{~d} t=\int_{t} \dot{G}\left[f\left(\boldsymbol{\sigma}_{0}\right)\right] \mathrm{d} t=G\left[f\left(\boldsymbol{\sigma}_{0}\right)\right]
$$

Substituting Eq. (A.14) in (A.5), the following expression for the rate of the mechanical dissipation at each damaged point is established

$$
\Xi=\Psi_{0} \dot{G}\left[f\left(\boldsymbol{\sigma}_{0}\right)\right]=\Psi_{0} \frac{\partial G\left[f\left(\boldsymbol{\sigma}_{0}\right)\right]}{\partial f\left(\boldsymbol{\sigma}_{0}\right)} \frac{\partial f\left(\boldsymbol{\sigma}_{0}\right)}{\partial \boldsymbol{\sigma}_{0}}: \mathrm{C}_{0}: \dot{\boldsymbol{\varepsilon}}
$$

The current value for the damage threshold $c$ can be written, at time $s=t$, as

$$
c=\max \left\{c^{\max }, \max \left\{\left.f\left(\boldsymbol{\sigma}_{0}\right)\right|_{s}\right\}\right\} \quad \forall 0 \leqslant s \leqslant t .
$$


There are several ways to define the damage threshold criterion. In this work, the exponential of Ref. [24] for concrete structures is used. The scalar function $G[\chi]$ (Eq. (A.11)) is here defined as a function of the unit normalized dissipation variable $\kappa$ as [19]

$$
\dot{\kappa}=K\left(\boldsymbol{\sigma}_{0}\right) \cdot \Xi_{m}=\left[\frac{r\left(\boldsymbol{\sigma}_{0}\right)}{g_{\mathrm{f}}}+\frac{1-r\left(\boldsymbol{\sigma}_{0}\right)}{g_{\mathrm{c}}}\right] \cdot \Xi_{m} \Rightarrow 0 \leqslant\left[\kappa=\int_{t} \dot{\kappa} \mathrm{d} t\right] \leqslant 1,
$$

where $\Xi_{m}=\Psi_{0} \dot{d}$ is the damage dissipation and $r(\boldsymbol{\sigma})=\sum_{I=1}^{3}\left\langle\sigma_{I}\right\rangle / \sum_{I=1}^{3}\left|\sigma_{I}\right|$ a scalar function to define the sign of the stress state at each point and at each time instant of the damage process, being $\langle x\rangle=0.5[x+|x|]$ the McAully function. The variables $g_{\mathrm{f}}$ and $g_{\mathrm{c}}$ are the maximum values for the tension-compression dissipation at each point, respectively [19]. By this way, the damage dissipation will be always normalized to the maximum consumed energy during the mechanical process.

Using $\kappa$ as an auxiliary variable, it is now possible to evaluate the damage function $G[\chi]$ in the following form [24]:

$$
d=G[c(\kappa)]=1-\frac{c^{\max }}{c(\kappa)} \mathrm{e}^{A\left(1-\frac{c(k)}{c \max }\right)} \quad \text { with } 0 \leqslant c^{\max } \leqslant c(d)
$$

but, under the damage condition $f\left(\boldsymbol{\sigma}_{0}\right) \equiv c(\kappa)$. This equation can be also written as

$$
G\left[f\left(\boldsymbol{\sigma}_{0}\right)\right]=1-\frac{f^{0}\left(\boldsymbol{\sigma}_{0}\right)}{f\left(\boldsymbol{\sigma}_{0}\right)} \mathrm{e}^{A\left(1-\frac{f\left(\boldsymbol{\sigma}_{0}\right)}{f^{0}\left(\boldsymbol{\sigma}_{0}\right)}\right)} \quad \text { with } f^{0}\left(\boldsymbol{\sigma}_{0}\right)=c^{\max },
$$

where $A=\left[g_{\mathrm{f}} /\left(f^{0}\left(\boldsymbol{\sigma}_{0}\right)\right)^{2}-0.5\right]^{-1}$ is a parameter depending on the fracture energy dissipation $g_{\mathrm{f}}[19]$. The value $f^{0}\left(\boldsymbol{\sigma}_{0}\right)=c^{\max }$ is obtained from the agreement with the first damage threshold, when the condition $G\left[f^{0}\left(\boldsymbol{\sigma}_{0}\right)\right]-G\left[c^{\max }\right]=0$ is reached and $G\left[f^{0}\left(\boldsymbol{\sigma}_{0}\right)\right]=G\left[c^{\max }\right] \equiv 0$ shows the damage integration algorithm for each single point of the structure.

Box A.1. Integration of the continuum damage equation at each structural point with exponential softening

1. Compute the elastic prediction stress and the internal variable at current time " $t+\Delta t$ ", and equilibrium iteration "i".

$$
\begin{aligned}
& {\left[\boldsymbol{\sigma}_{0}\right]^{t+\Delta t}=\mathrm{C}_{0}:[\boldsymbol{\varepsilon}]^{t+\Delta t}} \\
& { }^{i}[d]^{t+\Delta t} ; \quad \tau={ }^{i}\left[G\left[f\left(\boldsymbol{\sigma}_{0}\right)\right]\right]^{t+\Delta t} \\
& \tau^{0}={ }^{i}\left[G\left[f^{0}\left(\boldsymbol{\sigma}_{0}\right)\right]\right]^{t+\Delta t}
\end{aligned}
$$

2. Damage threshold checking:

(a) If $\tau-\tau^{\max } \leqslant 0$ :

Then $\left\{\begin{array}{ll}{ }^{i}[\boldsymbol{\sigma}]^{t+\Delta t}=\left[\boldsymbol{\sigma}_{0}\right]^{t+\Delta t} \\ { }^{i}[d]^{t+\Delta t} ; \quad \tau^{\max }=\tau\end{array}\right\} \quad$ and go to the EXIT

(b) If $\tau-\tau^{\max }>0$ :

Then start with the damage constitutive integration.

3. Integration of the damage constitutive equation,

$$
\begin{aligned}
& \tau^{\max }=\tau \\
& { }^{i}[d]^{t+\Delta t}=1-\left[\frac{\tau^{0}}{\tau} \mathrm{e}^{A\left(1-\frac{\tau}{\tau^{0}}\right)}\right]^{t+\Delta t}
\end{aligned}
$$

4. Stress and tangent constitutive tensor actualization.

$$
\begin{aligned}
& { }^{i}\left[\boldsymbol{\sigma}^{t+\Delta t}=\left(1-{ }^{i}[d]^{t+\Delta t}\right)\left[\boldsymbol{\sigma}_{0}\right]^{t+\Delta t}\right. \\
& { }^{i}\left[C^{T}\right]^{t+\Delta t}=\left[(1-d) C_{0}-\frac{\partial G\left[f\left(\boldsymbol{\sigma}_{0}\right)\right]}{\partial\left[f\left(\boldsymbol{\sigma}_{0}\right)\right]}\left[C_{0}: \boldsymbol{\varepsilon}\right] \otimes\left[\frac{\partial f\left(\mathrm{C}_{0}: \boldsymbol{\varepsilon}\right)}{\partial \boldsymbol{\varepsilon}}\right]\right]^{t+\Delta t}
\end{aligned}
$$


The Simo and $\mathrm{Ju}$ stress function $[37,38]$ is used in the paper

$$
\tau=f\left(\boldsymbol{\sigma}_{0}\right)=\sqrt{2 \Psi_{0}(\boldsymbol{\varepsilon})}=\sqrt{\varepsilon: C_{0}: \varepsilon} .
$$

Taking into account this function, parameter $A$ used in Eq. (A.18) can be written as

$$
A=\frac{1}{\frac{g_{\mathrm{f}}}{\left(f^{0}\left(\boldsymbol{\sigma}_{0}\right)\right)^{2}}-\frac{1}{2}},
$$

where $g_{\mathrm{f}}$ represents the maximum of the fracture energy to be dissipated at each point of the solid and $f^{0}\left(\boldsymbol{\sigma}_{0}\right)$ is the value given by the threshold equation for the first damage threshold.

\section{References}

[1] ABAQUS. User Manual, Hibbit Karlsson and Sorensen, HKS, Version 5.8, 1999.

[2] R. Aguiar, A.H. Barbat, Daño sísmico en estructuras de hormigón armado, Universidad Politécnica del Ejercito, Quito, Ecuador, 1997.

[3] S. Arman, M. Grigoriu, Markov model for local and global damage indexes in seismic analysis, NCEER-94-0003, National Center for Earthquake Engineering Research, 1994.

[4] A.H. Barbat, S. Oller, E. Oñate, A. Hanganu, Viscous damage model for Timoshenko beam structures, Int. J. Solids Struct. 34 (30) (1997) $3953-3976$.

[5] E. Car, S. Oller, E. Oñate, An anisotropic elastoplastic constitutive model for large strain analysis of fiber reinforced composite materials, Comput. Methods Appl. Mech. Engrg. 185 (2-4) (2000) 245-277.

[6] J. Chaboche, Continuum damage mechanics. Part I. General concepts, J. Appl. Mech. 55 (1988) 59-64.

[7] J. Chaboche, Continuum damage mechanics. Part II. Damage growth, J. Appl. Mech. 55 (1988) 65-72.

[8] R.W. Clough, J. Penzien, Dynamics of Structures, McGraw-Hill, 1992.

[9] G. Duma, S. Seren, Determination of basic seismological parameters for the Warth Bridge site, Technical report CIMG, Department of Geophysics, Austria, 1998.

[10] R. Faria, N. Vila Pouca, R. Delgado, Simulation of the cyclic behaviour of r/c rectangular hollow section bridge piers via a detailed numerical model, J. Earthquake Engrg. 8 (5) (2004) 725-748.

[11] R.G. Flesch, P.H. Kirkegaard, C. Kramer, M. Brughmans, G.P. Roberts, M. Gorozzo, Dynamic in situ test of bridge WARTH/Austria, Technical report, TU-Graz, TUG TA 99/0125, 1999.

[12] C. Gómez-Soberón, S. Oller, A. Barbat, Seismic vulnerability of bridges using simple models, Monographs of Seismic Engineering, Monograph series in Earthquake Engineering, CIMNE IS-47, International Center of Numerical Methods in Engineering, Barcelona, Spain, 2002.

[13] D. Hull, Materiales compuestos, Reverté Editorial, Spain, 1987.

[14] J.E. Hurtado, A.H. Barbat, Monte Carlo techniques in computational stochastic mechanics, Arch. Comput. Methods Engrg. 5 (1) (1998) 3-30.

[15] L.M. Kachanov, Time of rupture process under creep conditions, Izvestia Akaademii Nauk; Otd Tech Nauk 8 (1958) 26-31.

[16] J. Lemaitre, A Course on Damage Mechanics, second ed., Springer, 1992.

[17] J. Lemaitre, J.L. Chaboche, Aspects phénoménologiques de la rupture par endommagement, J. Appl. Mech. 2 (1978) 317-365.

[18] W.A. Lenhard, Regional earthquake hazard in Austria, in: Proceedings of the 10th European Conference on Earthquake Engineering, Vienna, Austria, vol. I, 1994, pp. 63-68.

[19] J. Lubliner, J. Oliver, S. Oller, E. Oñate, A plastic damage model for non linear analysis of concrete, Int. Solids Struct. 25 (3) (1989) $299-326$.

[20] B. Luccioni, S. Oller, A directional damage model, Comput. Methods Appl. Mech. Engrg. 192 (9-10) (2003) 1119-1145.

[21] B. Luccioni, S. Oller, R. Danesi, Coupled plastic-damaged model, Comput. Methods Appl. Mech. Engrg. 129 (1-2) (1996) 81-89.

[22] G.A. Maugin, The Thermomechanics of Plasticity and Fracture, Cambridge University Press, 1992.

[23] M. Menegotto, P.E. Pinto, Slender RC compressed members in biaxial bending, J. Struct. Div., ASCE 103 (3) (1977) $587-605$.

[24] J. Oliver, M. Cervera, S. Oller, J. Lubliner, Isotropic damage models and smeared crack analysis of concrete, in: Second International Conference on Computer Aided Analysis and Design of Concrete Structures, Austria, vol. 2, 1990, pp. 945-958.

[25] S. Oller, E. Car, J. Lubliner, Definition of a general implicit orthotropic yield criterion, Comput. Methods Appl. Mech. Engrg. 192 (7-8) (2003) 895912.

[26] S. Oller, B. Luccioni, A. Barbat, Un método de evaluación del daño sísmico de estructuras de hormigón armado, Revista Internacional de Métodos Numéricos para el Cálculo y Diseño en Ingeniería 12 (2) (1996) 215-238.

[27] S. Oller, A.H. Barbat, E. Oñate, A. Hanganu, A damage model for the seismic analysis of buildings structures, in: 10th World Conference on Earthquake Engineering, 1992, pp. 2593-2598.

[28] S. Oller, E. Oñate, J. Miquel, S. Botello, A plastic damage constitutive model for composite material, Int. J. Solids Struct. 33 (17) (1996) $2501-2518$.

[29] S. Oller, O. Salomón, E. Oñate, A continuum mechanics model for mechanical fatigue analysis, Comput. Mater. Sci. 32 (2005) $175-195$.

[30] ÖNORM B4015-2, Belastungsannhmen im bauwesen. Außergenwöhnliche einwirkungen erdbebeneinwirkungen grundlagen, 1998.

[31] G.F. Panza, F. Romanelli, F. Vaccari, Effects on bridge seismic response of asynchronous motion at the base of the bridge piers, Report 5/1, 2, 3F, International Center of Theoretical Physics (ICTP), Trieste, Italy, 2001.

[32] Y.J. Park, A.H. Ang, Mechanistic seismic damage model for reinforced concrete, J. Struct. Engrg. 111 (4) (1985) $722-739$.

[33] M. Petrangeli, P.E. Pinto, V. Ciampi, Fiber element for cyclic bending and shear of RC structures. I: Theory, J. Engrg. Mech., ASCE 125 (9) (1999) 994-1001.

[34] M. Petrangeli, Fiber element for cyclic bending and shear of RC structures. II: Verification, J. Engrg. Mech. ASCE 125 (9) (1999) 1002-1009. 
[35] A. Pinto, J. Molina, G. Tsionis, Cyclic Test on a Large Scale Model of an Existing Short Bridge Pier (Warth Bridge-Pier A70), EUR Report, Joint Research Centre, ISIS, Ispra, Italy.

[36] J.M. Puig, E. Car, S. Oller, Solution for the inelastic buckling of long fiber reinforced composite materials, in: Composites in Construction International Conference, A. Balkema, 2001, pp. 119-124.

[37] J. Simo, J. Ju, Strain and stress based continuum damage models-I. Formulation, Int. J. Solids Struct. 23 (1987) 821-840.

[38] J. Simo, J. Ju, Strain and stress based continuum damage models-II. Computational aspects, Int. J. Solids Struct. 23 (1987) 841-869.

[39] O. Zienkiewicz, R. Taylor, The Finite Element Method, vols. 1 and 2, fourth ed., McGraw-Hill, 1988. 